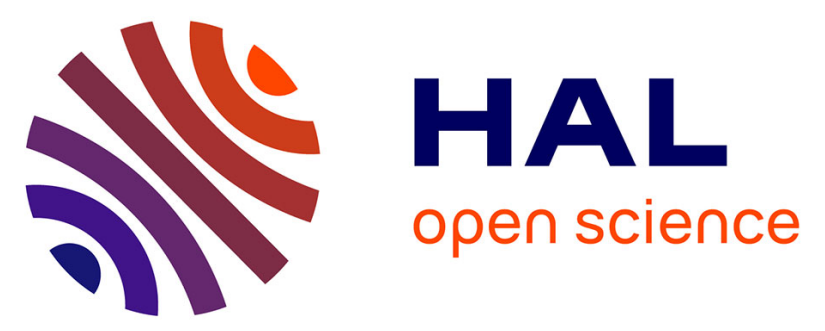

\title{
Dietary intake estimate for perfluorooctanesulphonic acid (PFOS) and other perfluorocompounds (PFCs) in English retail foods following determination using standard addition LC-MS/MS
}

Don Brian Clarke, Antony Lloyd, Simon Hird, David Mortimer, Martin Gem, Victoria Adele Bailey, Anne Routledge

\section{To cite this version:}

Don Brian Clarke, Antony Lloyd, Simon Hird, David Mortimer, Martin Gem, et al.. Dietary intake estimate for perfluorooctanesulphonic acid (PFOS) and other perfluorocompounds (PFCs) in English retail foods following determination using standard addition LC-MS/MS. Food Additives and Contaminants, 2010, 27 (04), pp.530-545. 10.1080/19440040903476590 . hal-00577002

\author{
HAL Id: hal-00577002 \\ https://hal.science/hal-00577002
}

Submitted on 16 Mar 2011

HAL is a multi-disciplinary open access archive for the deposit and dissemination of scientific research documents, whether they are published or not. The documents may come from teaching and research institutions in France or abroad, or from public or private research centers.
L'archive ouverte pluridisciplinaire HAL, est destinée au dépôt et à la diffusion de documents scientifiques de niveau recherche, publiés ou non, émanant des établissements d'enseignement et de recherche français ou étrangers, des laboratoires publics ou privés. 


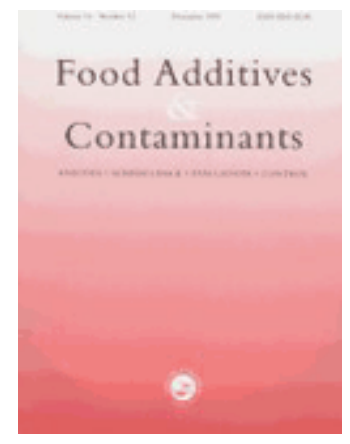

\section{Dietary intake estimate for perfluorooctanesulphonic acid (PFOS) and other perfluorocompounds (PFCs) in English retail foods following determination using standard addition \\ LC-MS/MS}

\begin{tabular}{|c|c|}
\hline Journal: & Food Additives and Contaminants \\
\hline Manuscript ID: & TFAC-2009-334.R1 \\
\hline Manuscript Type: & Original Research Paper \\
\hline $\begin{array}{r}\text { Date Submitted by the } \\
\text { Author: }\end{array}$ & 04-Nov-2009 \\
\hline Complete List of Authors: & $\begin{array}{l}\text { Clarke, Don; Food and environment research agency, Contaminants } \\
\text { and authenticity programme } \\
\text { Lloyd, Antony; Food and environment research agency, } \\
\text { Contaminants and authenticity programme } \\
\text { Hird, Simon; Food and environment research agency, Chemical } \\
\text { residues programme } \\
\text { Mortimer, David; Food Standards Agency, Food safety: } \\
\text { contaminants division } \\
\text { Gem, Martin; Food Standards Agency, Food safety: contaminants } \\
\text { division } \\
\text { Bailey, Victoria; Food Standards Agency, Food safety: contaminants } \\
\text { division; University of York, Department of Chemistry } \\
\text { Routledge, Anne; University of York, Department of Chemistry }\end{array}$ \\
\hline Methods/Techniques: & Chromatography - LC/MS, Survey \\
\hline Additives/Contaminants: & Environmental contaminants \\
\hline Food Types: & \\
\hline
\end{tabular}




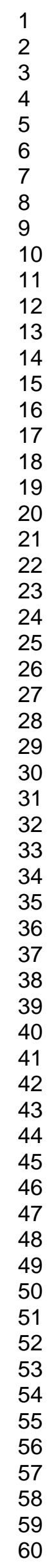

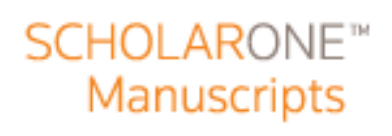

7

25

26

27

29

30

32

33

34

35

36

37

39

40

41

42

44

45

46

48

49

50

52

53

54

56

57

58

60

http://mc.manuscriptcentral.com/tfac Email: fac@tandf.co.uk 


\title{
Dietary intake estimate for perfluorooctanesulphonic acid (PFOS) and other perfluorocompounds (PFCs) in English retail foods following determination using standard addition LC-MS/MS
}

\author{
D. B. Clarke* V. A. Bailey ${ }^{\dagger}$ A. Routledge ${ }^{\dagger}$, A. S. Lloyd, S. Hird, D. N. Mortimer ${ }^{+}$, \\ M. Gem ${ }^{+}$
}

Food and Environment Research Agency, Department for Environment, Food and Rural Affairs, Sand Hutton, York, YO41 1LZ, UK; ${ }^{\dagger}$ The Department of Chemistry, University of York, Heslington, York, YO10 5DD, UK; ${ }^{+}$Food Standards Agency, 125 Kingsway, London WC2B $6 \mathrm{NH}$

\begin{abstract}
The analysis of 252 food samples (UK-produced and imported) purchased from a variety of retail outlets in England was undertaken for the presence of PFOS, PFOA and nine other PFCs. A limit of quantification (LOQ) of $1 \mu \mathrm{g} / \mathrm{kg}$ was achieved for all target analytes, in all samples. Standard addition was used for quantification of PFC levels. All eleven of the targeted PFCs were detected, in 75 of the individual foods. In $70 \%$ of the samples, including all meat other than offal, none of the analytes were present at above the LOD. The highest levels found were $59 \mu \mathrm{g} / \mathrm{kg}$ of perfluorooctanesulfonic acid (PFOS) and $63 \mu \mathrm{g} / \mathrm{kg}$ total PFCs ( $\Sigma$ PFCs) in an eel sample, and $40 \mu \mathrm{g} / \mathrm{kg}$ PFOS (62 $\mu \mathrm{g} / \mathrm{kg} \Sigma$ PFCs) in a whitebait sample. The highest level in an offal sample was $10 \mu \mathrm{g} / \mathrm{kg}$, in a wild roe deer liver. There were 6 samples with $\Sigma$ PFCs $>15 \mu \mathrm{g} / \mathrm{kg}$ (fish, shellfish, crustaceans), a further 7 samples with $\Sigma$ PFCs $11-15 \mu \mathrm{g} / \mathrm{kg}$ (including a liver), nine with $\Sigma$ PFCs 6-10 $\mu \mathrm{g} / \mathrm{kg}$ (fish and livers), 31 with $\Sigma$ PFCs $2-5 \mu \mathrm{g} / \mathrm{kg}$ (including kidneys, popcorn and processed peas) and a further 22 with $\Sigma$ PFCs close to the LOD of $1 \mu \mathrm{g} / \mathrm{kg}$ (including eggs and potatoes). These concentrations indicate that English consumers are being exposed to a low level of PFC contamination from food. The estimated upper bound dietary intake of $10 \mathrm{ng} / \mathrm{kg}$ bodyweight/day of PFOS for average adult consumers is well below the $0.15 \mu \mathrm{g}$ (150 ng)/kg bw Tolerable Daily Intake (TDI) set by the European Food Safety Authority.
\end{abstract}




\section{Introduction}

PFOS is now the generally accepted term referring to the individual chemical perfluorooctanesulphonic acid and any closely related compounds that contain the PFOS moiety $\left(\mathrm{C}_{8} \mathrm{~F}_{17} \mathrm{SO}_{2}\right)$, including those that may potentially degrade to PFOS in the environment (Brooke 2004). This term is often used interchangeably with PerFluoro Compounds (PFCs), or PerFluoroAlkylated Substances (PFAS). The chemicals under consideration are best described as an homologous series of fullyfluorinated sulphonic acids, and these homologues can also be present as sulphonamide or carboxylic acid derivatives. The high-energy carbon-fluorine covalent bond makes the core perfluoroalkyl group resistant to hydrolysis, photolysis and microbial or mammalian metabolism. Standard metabolic processes can remove other constituents such as hydrocarbon groups. There are believed to be important introversions of larger to smaller molecular weight PFCs occurring in the environment. PFOS is therefore not readily degradable and can persist and bioaccumulate in the environment, probably by means of covalent protein binding. The US Environmental Protection Agency (EPA) reported in May 2000 that PFOS combines persistence, bioaccumulation and toxicological properties to an extraordinary degree. PFOS exhibits hepatotoxicity, neurotoxicity, carcinogenicity and reproductive toxicity. One of the most disturbing findings was its unusual ability to influence second-generation rodent reproduction at $0.4 \mathrm{mg} / \mathrm{kg}$ body weight per day (bw/day) (repeated daily dosing). PFCs are also known to be endocrine disruptors (Jensen 2008). 
PFOS has global biospheric distribution, bioaccumulation and biomagnification patterns similar to other persistent organic pollutants (POPs). A recent review provides an up-to-date reference for sources, fate and transport of perfluorocarboxylates (Prevedouros 2006). The increases in global exposure levels, have led to elevated circulatory concentrations of PFOS in mammalian plasma. Retrospectively, this upward trend has been apparent for some decades. Aside from industrial exposure, it is not yet clear as to the exact mechanisms of exposure to specific fluorochemicals and their precursors, or their relative significance, e.g. via fire fighting foam, household and consumer products $v s$ food and water, vs air and dust.

Historically the uses of PFOS have been widespread and include uses as; a metal surface treatment, as a fabric protector (stain repellents - carpets), impregnated in paper (grease proofing - pizza boxes), and leather, in waxes, polishes, paints, varnishes and cleaning products. In Europe the suggested scale of use is 80 tons of PFOS used between 1980 and 2005 by the North Sea oil industry (fire fighting) and an equivalent usage/emission as total European terrestrial pollution.

$3 \mathrm{M}$, the major PFC producer, had reduced PFOS production by $98 \%$ by the end of 2000 (equivalent to an $88 \%$ reduction in world-wide production), with total cessation in 2002 (Olsen 2008, Spliethoff 2008). The global regulation of PFOS/PFOA, together with the voluntary change to alternative products that is already well underway in Westernised countries, should result in a decline in future environmental contamination and hence human exposure. The first declines in human exposure in localised areas have already been reported. The high human exposure to PFCs in North America led to this population and the blood samples collected by the American Red Cross, being the most highly contaminated in the world. However, their PFOS levels appear to have peaked, and are now declining in line with the previously reported half-life of 4-5 years in adult humans (Olsen 2008). A similar decline has very recently been observed in infants (Spliethoff 2008). While declines in US exposure to PFCs appear to have followed the fall in US production, this is not the case globally. PFOS levels appear to be continuing to increase in blood samples taken from Chinese citizens (Jin 2007). 
As the estimated half-life of PFOS in the environment is 41 years, the legacy of environmental contamination cannot be expected to be solved rapidly. One of the clearest examples of a temporal trend in the food chain was seen in guillemot eggs obtained from a Baltic island, where the guillemots feed on fish from the Baltic Sea, thus reflecting the general level of contamination in the region. The concentration in eggs rose at an almost linear rate of $18 \mu \mathrm{g} / \mathrm{kg} /$ per year between 1968-2003, increasing from $17 \mu \mathrm{g} / \mathrm{kg}$ in 1968 to $623 \mu \mathrm{g} / \mathrm{kg}$ in 2003 (Holmstrom 2005). As these eggs are a human food source, the trend seen in these eggs can be directly correlated with the human food chain.

Various regulatory limits for acceptable levels of PFOS in the environment are being discussed. The European Food Safety Authority (EFSA) identified $0.03 \mathrm{mg} / \mathrm{kg}$ bw per day of PFOS as the lowest no-observed-adverse-effect level (NOAEL, liver pathology) for monkeys and considered this suitable for deriving a human Tolerable Daily Intake (TDI) for PFOS of $0.15 \mu \mathrm{g} / \mathrm{kg}$ bw. Similarly a ten-fold higher human TDI for PFOA of $1.5 \mu \mathrm{g} / \mathrm{kg}$ bw has also been agreed (EFSA 2008).

To date there have been very few studies that have determined PFCs in the human diet. The prevalence of PFOS and its impact on the wider human food chain only became apparent when the 3M Multi-City Study reported that four of the twelve positive food concentrations were from 'control' cities, i.e., those without a fluorochemical industry (3M Company, 2001). The emerging data on the concentrations of PFCs in food throughout the world are forming a picture of a generally low-level contamination in the wider diet, but with individual "hot spots" occurring within the fish and offal food groups. A survey of Swedish Total Diet Study (TDS) food composites (Berger 2007) focused on the four most likely food groups to be contaminated; meat products, dairy products, eggs and seafood. This survey did not positively identify any PFCs and reported less than the LOD $(2.2,3.2 \mu \mathrm{g} / \mathrm{kg}$ PFOS and PFOA, respectively) for all food composites surveyed. However, individual fish samples were found to contain up to $23 \mu \mathrm{g} / \mathrm{kg}$ PFOS (Berger 2007). A Spanish survey of composite foodstuffs found numerous trace levels of PFOS with a maximum of 0.8 $\mu \mathrm{g} / \mathrm{kg}$ (Ericson 2008). A larger Canadian TDS study reported a maximum level of 5 $\mu \mathrm{g} / \mathrm{kg}$ perfluorononanoic acid (PFNA) in beefsteak. PFOS was measured at $2.7 \mu \mathrm{g} / \mathrm{kg}$ in beefsteak, $2.6 \mu \mathrm{g} / \mathrm{kg}$ in marine fish, $2.1 \mu \mathrm{g} / \mathrm{kg}$ in ground beef and $2.0 \mu \mathrm{g} / \mathrm{kg}$ in 
freshwater fish (Tittlemier 2007). A large 7-day duplicate diet study in Germany reported average values from 214 separate daily diets collected from 31 adults as 0.06 and $0.69 \mu \mathrm{g} / \mathrm{kg}$ for PFOS and PFOA, respectively (Fromme 2007). For adults consuming $2.5 \mathrm{~kg}$ of food (solid and liquid) this represented mean daily dietary intakes of 123 and $270 \mathrm{ng}$ of PFOS and PFOA, respectively, equivalent to 1.8 and 3.9 ng/kg bw/day. The duplicate diet collection model was therefore not dissimilar in outcome to the TDS model with regard to the intake estimates. Of interest in this study was the detailed analysis of each day's food in which just two PFOA values were unusually high. The higher of these was a concentration of $118 \mu \mathrm{g} / \mathrm{kg}$ in the daily diet. This one-off high value was undoubtedly from smaller portions of a single discrete foodstuff containing at least an order of magnitude higher concentration. This again is consistent with the emerging knowledge on upper-end $\mathrm{mg} / \mathrm{kg}$ contamination levels in some European freshwater fish from heavily polluted industrialized areas.

In order to put European and UK data into context, recent work in Japan (Guruge 2008) reported cattle, pig and chicken livers to contain mean PFOS concentrations of 34, 54 and $67 \mu \mathrm{g} / \mathrm{kg}$, respectively, with the highest individual PFOS value at 92 $\mu \mathrm{g} / \mathrm{kg}$ in a chicken liver. Chinese chicken eggs were all found to contain PFOS in the range of $45-87 \mu \mathrm{g} / \mathrm{kg}$ (Wang 2008). Oysters from Tokyo bay contained $3 \mu \mathrm{g} / \mathrm{kg}$ of PFOS (So 2006).

The aim of the survey was to develop more robust analytical methods, in particular to lower the limit of detection, to enable improved estimates of dietary intakes of the chemicals and to provide data to inform negotiations regarding possible future limits for the chemicals in foods.

\section{Materials and methods}

\section{Collection and preparation of food samples}

Priority was given to foods in which the chemicals had been detected in the previous survey (potatoes and vegetables (FSA 2006), and foods in which it was anticipated that the chemicals would be present on the basis of literature reports (fish and offal). 
A total of 252 samples of various foods (fish, liver, kidney, meat, cheese, milk, eggs, potatoes, vegetables, cereals and jam) were obtained by Ventress Technical Limited Ventress Technical Limited is an independent consultancy with specialist skills in the practice of food technology, food examinations and offers varied services to science and technology. Using trained sampling personnel and comprehensive field management information systems, it has many years experience of sampling a variety of food products, from bulk consignments on site to individual retail packs on retail sale. The samples for this survey were purchased from retail establishments in ten regions of the UK (covering all four countries but weighted towards England as the most populated of the countries), in two phases, the first in 2007. The second phase, used to follow up on foods in which higher concentrations of the chemicals had been found in phase 1, took place in 2008.

The retail establishments included major and smaller national supermarkets and independent retailers (including convenience stores, butchers, fishmongers, health food shops, farm shops, ethnic stores, licensed market stalls and mail order/internet sales). In selecting the retail establishments and numbers of samples obtained from each, a balance was struck between the relative market shares are supermarkets vs independent retailers and the need to cover a large number of establishments and locate some foods not widely available. All sampling was random. All samples were stored and transported to the Food and Environment Research Agency Laboratory, which carried out the analyses, mostly under similar conditions to those that prevailed when they were on sale. Approximately $400 \mathrm{~g}$ of each individual retail food was homogenised and extracted without any further processing. However certain meat and fish samples were frozen immediately after purchase and held in a frozen state throughout further storage and transfer stages to prevent microbial deterioration. The types of foods are described briefly in Table1. All other food samples and reference materials referred to in this report were obtained by the authors and were used for method development, method validation and quality assurance (QA) purposes only.

\section{Chemicals}

All solvents were of HPLC grade. Ammonium acetate (99.99\%), acetic acid (glacial), potassium hydroxide pellets were supplied by Sigma (Poole, UK). All other reagents, 
solvents and chemicals were of analytical grade, specific LC-MS grade or equivalent. Strata XAW weak anion exchange SPE cartridges (6 cc/200 mg, $33 \mu \mathrm{m})$ were supplied by Phenomenex (Macclesfield, UK). All glassware was either washed three times with methanol or heated to $600^{\circ} \mathrm{C}$, and silyanised before use.

\section{Standards}

The individual PFCs and internal standards are listed in Table 2. PFOS (perfluorooctanesulphonic acid), PFHxSK (potassium perfluorohexanesulphonic acid) and PFHxA (perfluorohexanoic acid) were supplied by Fluka (Gillingham, UK), PFHpA (perfluoroheptanoic acid), PFOA (perfluorooctanoic acid), PFNA (perfluorononanoic acid), PFDeA (perfluorodecanoic acid), PFUnA (perfluoroundecanoic acid), PFDoA (perfluorododecanoic acid) and PFBSH (perfluorobutanesulphonic acid) and $3 \alpha, 12 \alpha$-dihydroxy-5 $\beta$-cholic acid- $N$-(2sulfoethyl)-amide (taurodeoxycholic acid, TDCA) were supplied by Sigma (Poole, UK). PFOSA (perfluorooctanesulphonamide) and TH-PFOS (tetrahydro-PFOS) were supplied by ABCR GmbH (Karlsruhe, Germany), ${ }^{13} \mathrm{C}_{4}$-PFOA, ${ }^{13} \mathrm{C}_{2}$-PFDeA, D $-n$-EtFOSE (2-( $N$ - $\mathrm{D}_{5}$-ethylperfluoro-1-octanesulfonamido)- $\mathrm{D}_{4}$-ethanol) and $\mathrm{D}_{3}-n$-MeFOSA ( $N$ - $\mathrm{D}_{3}$-methylperfluoro-1-octanesulphonamide) were supplied by Greyhound Chromatography (Birkenhead, UK). Stock standards of those not already in solution were prepared at $1 \mathrm{mg} / \mathrm{ml}$ in methanol and stored at $+4^{\circ} \mathrm{C}$. Stock solution volumes were monitored by recording the weight before and after each aliquot was removed, to check for possible losses of solvent due to evaporation. Working solutions and mixtures were prepared fortnightly and also stored at $+4^{\circ} \mathrm{C}$. All fluorinated chemicals and reagents were assessed for purity and possible PFC cross contamination. For PFC analytical standards, the area responses of all multiple reaction monitoring (MRM) transitions in each separate $0.5 \mu \mathrm{g} / \mathrm{ml}$ solution in methanol were measured and assessed as a percentage of the total ion response [assuming equal ionization]. Chemical purities were all $>90 \%$, so no corrections were considered to be necessary.

\section{Sample extractions}

Quadruple 10 g portions of each homogenised food were weighed out into Falcon tubes $(50 \mathrm{ml})$. The appropriate volumes of internal standard (IS) and standard addition 
mixtures were added to prepare two unspiked portions; one overspiked at the reporting level $(1 \mu \mathrm{g} / \mathrm{kg})$ and one at 10-times the reporting level $(10 \mu \mathrm{g} / \mathrm{kg})$. The food portions were homogenised for 1-3 mins as required in $20 \mathrm{ml}$ of methanol with an Ultra Turrax (T25 basic with S25N blade). Once homogenised, more methanol was added ( $c a .40 \mathrm{ml}$ in total) and mixed, while withdrawing the Ultra Turrax blade. Samples were shaken vigorously overnight (16 h), then centrifuged (15 min, 5000 rpm) (Tittlemier 2007). Eggs and milk samples required heating at $70^{\circ} \mathrm{C}$ for $2 \mathrm{hr}$ to induce protein precipitation. The supernatant methanol extracts were evaporated under a nitrogen stream $\left(80^{\circ} \mathrm{C}\right.$, in silanised glass vials) just to dryness, and the residues were re-dissolved in aqueous $\mathrm{KOH}(25 \mathrm{ml}, 0.01 \mathrm{M}$, sonication $10 \mathrm{~min})$. The aqueous solutions were then re-centrifuged (15 min, $5000 \mathrm{rpm}$ ). When required, the supernatants were poured in one continuous gentle movement, without breaking up the floating materials [fat] or disturbing the sediment, into a funnel connected onto the top of a preconditioned SPE cartridge (weak anion exchange)(Taniyasu 2005). Where clear solutions with no floating matter were obtained, these were simply added in repeated ca. $5 \mathrm{ml}$ portions to the cartridges as the eluent went through (to $c a .1 \mathrm{ml}$ remaining). The cartridges were loaded at a constant drip rate, by increasing from gravity feed to full vacuum as required. After loading, the cartridges were washed with ammonium acetate $(2 \times 6 \mathrm{ml}, 25 \mathrm{mM}, \mathrm{pH} 4.5)$ and eluted with basic methanol (4 $\mathrm{ml}, 0.1 \%$ ammonia). The eluates were reduced under a stream of nitrogen gas $\left(60^{\circ} \mathrm{C}\right)$, just to dryness and the residues taken up in methanol (400 $\mu$, sonication $10 \mathrm{~min}$ ). Extracts were transferred into silanised glass microvials $(300 \mu \mathrm{l})$ for LC-MS/MS determination.

The analysis of cheeses was particularly problematic, due to the excessive amount of material ( $c a .50 \mathrm{mg}$ ) left after the standard clean-up. The clean-up method was therefore extended. The residue was halved by elution of neutral amides off the SPE in methanol $(4 \mathrm{ml}$, neutral $\mathrm{pH})$, and then treating this fraction as a separate extract. Acids, both sulphonic and carboxylic were then eluted as before, using basic methanol (4 ml, $0.1 \%$ ammonia). Each fraction still contained ca. $25 \mathrm{mg}$ of coextractives. A fluorous solvent mixture was then used to partition fluorinated from non-fluorinated compounds by liquid-liquid extraction (F-LLE). SPE eluates (neutral or basic) were dried and then redissolved in dichloromethane $(10 \mathrm{ml}$, DCM saturated with water) by sonicating for $10 \mathrm{~min}$. Trifluoroethanol $(7.5 \mathrm{ml})$ and perfluorohexane (FC-72, $2.5 \mathrm{ml})$ 
were added, the mixture was shaken $(1 \mathrm{~min})$, and then sonicated for $10 \mathrm{~min}$. When the residues were in solution, the resulting triphasic system was heated to $80^{\circ} \mathrm{C}$ for one hour to achieve a monophasic mixture. The mixtures were then cooled to $-70^{\circ} \mathrm{C}$ for one hour and the upper $10 \mathrm{ml}$ of DCM was pipetted out and discarded as the nonfluorinated fraction. The lower two fluorous layers were pipetted out together and dried under a stream of nitrogen gas $\left(30^{\circ} \mathrm{C}\right)$ until just dry, and the residues taken up in methanol (400 $\mu$ l, sonicated for $10 \mathrm{~min})$. Extracts were transferred into silanised glass microvials $(300 \mu \mathrm{l})$ for determination by LC-MS/MS.

\section{Chromatography and quantification}

Analysis was undertaken by LC-MS/MS. A CTC Pal autosampler (Presearch, UK) and an HP1100 HPLC system with column oven (Agilent, UK) were coupled to an API4000 triple quadrupole mass spectrometer (MDS Sciex Instruments, UK). The guard cartridge was $\mathrm{C}_{8}$. The HPLC column $(5 \mu \mathrm{m}, 60 \AA, 2.1 \times 150 \mathrm{~mm})$ was Fluorosep RP Octyl phase, thermostatically held at $30^{\circ} \mathrm{C}$ in the column oven. The injection volume was generally $10 \mu \mathrm{l}$. The gradient programme (methanol: aqueous ammonium formate, $5 \mathrm{mM}, \mathrm{pH} 4$ ) was: $10 \%$ methanol increasing to $30 \%$ at $0.1 \mathrm{~min}$ (linear gradient), to $75 \%$ at $7 \mathrm{~min}$ and $100 \%$ methanol at $10 \mathrm{~min}$, this was held for 5 min (column washing), then decreased to $10 \%$ methanol at $15.1 \mathrm{~min}$, this was held 4.9 min at $10 \%$ methanol (column re-conditioning). The eluate was diverted to the mass spectrometer between 7 and $19.5 \mathrm{~min}$, whereas from 0-7 and 19.5-20 $\mathrm{min}$ it was discarded by valve switching to waste, in order to protect the ion source. A summary of MRM transitions, retention times and solvent-based LODs of the PFC analytical standards are given in Table 2. Analyst 1.4.2 software was used for instrument control, file acquisition and peak integration. The MS detector in MRM mode with a Turbo Ion Spray source was used for quantitative analysis. Data acquisition was conducted in one simultaneous acquisition schedule. Instrumental parameters were optimised by infusion of standard solutions directly into the MS detector $(1 \mu \mathrm{g} / \mathrm{ml}$ in 1:1 methanol: aqueous ammonium formate ( $5 \mathrm{mM}, \mathrm{pH} 4)$. The Turbo Ion Spray (TIS) conditions were; turbo-gas 50 psi, curtain-gas 12 psi, nebuliser-gas 50 psi, desolvation temperature $450^{\circ} \mathrm{C}$. An Excel spreadsheet was used to calculate PFC concentrations from the standard additions. The standard addition calculation approach is illustrated 
in Figure 1, with representative chromatograms demonstrating the response of the less sensitive but highly selective secondary qualifying ion for PFOS in Figure 2.

\section{Analytical quality assurance}

Stock standard solutions were prepared at $1 \mathrm{mg} / \mathrm{ml}$ in methanol and stored at $4^{\circ} \mathrm{C}$. Dilutions of these were prepared bi-weekly to minimise surface binding or evaporation losses. Dispensing of stock solutions was monitored for any possible losses, due to evaporation, by weighing. Working solutions of mixed standards were prepared at 5 and $0.5 \mu \mathrm{g} / \mathrm{ml}$ in methanol for spiking. Foods ( $10 \mathrm{~g})$ were overspiked at 1 and $10 \mu \mathrm{g} / \mathrm{kg}$ by addition of $20 \mu \mathrm{l} @ 0.5$ or $5 \mu \mathrm{g} / \mathrm{ml}$ of a mixed standards solution. Tetrahydro-PFOS (TH-PFOS), ${ }^{13} \mathrm{C}_{4}$-PFOA, ${ }^{13} \mathrm{C}_{4}$-PFOS, ${ }^{13} \mathrm{C}_{2}$-PFDeA, D $-n$-Et-FOSE and $\mathrm{D}_{3}-n$-Me-FOSEA were used as internal standards (IS) by addition of $200 \mu \mathrm{l} @ 0.5$ $\mu \mathrm{g} / \mathrm{ml}$ of a mixed solution, giving a $10 \mu \mathrm{g} / \mathrm{kg}$ IS addition level. Each food sample was analysed in duplicate throughout the entire extraction method to ensure that advantageous point contamination was not mistaken for the presence of any native PFC. Each sample was also overspiked at a minimum of two concentrations $(1 \& 10$ $\mu \mathrm{g} / \mathrm{kg}$ ). For a specific analyte to be considered present in a sample extract the following criteria had to be met: i) the relative retention times of the analyte had to be comparable to those of a retention time marker, an internal standard, and to authentic analytical standards of each analyte; ii) the peak had to have the correct mass transition, maximising at the correct retention time; iii) the signal to noise ratio of any peak had to be greater than $3: 1$. In order to prove the absence of a given PFC, the internal standard had to be present in all extracts, the blank extract had to show no signal at the retention time of the target PFC, whilst the overspiked extracts had to show a peak for the target PFC at the required retention time. As many of the foods behave differently with respect to extraction, recovery of analytes through the SPE stages and matrix induced suppression of ionisation, a single LOD (reporting level) for all foods or all target PFCs was not possible. In the absence of any suitable certified reference material (CRM), a number of samples from previous surveys that had been found to contain measurable levels of specific PFCs were re-analysed to demonstrate inter-batch reproducibility (Table 3).

\section{Dietary intakes}


Calculations were performed by the UK Food Standards Agency using the Intake2 programme. Intake 2 is the FSA in-house system supplied by Dietica for assessing exposure to chemicals in the food we eat and conducting nutrition and consumption assessments using NDNS (National Diet and Nutrition Survey) data. Intake2 is comprised of a bespoke VB front end and a Sagent back end database containing the NDNS consumption surveys, Nutrient information on all foods, and recipe composition data. Users set up a food group containing foods of interest and, if required, the system identifies recipes containing these foods and the percentage within the recipe. For intake assessments, users apply levels of chemicals to the foods selected. Intake2 essentially identifies which consumers have eaten the foods of interest, the amount eaten, and the level of or contaminants within the foods, and provides summary distributional analyses across consumers or the survey population.

All calculations are consumer-based, i.e. where only those who eat a particular food item are included in the calculations, rather than the data being averaged over the whole population. Average and individual age group estimates are calculated based on the most recent UK consumption data for the elderly (65 years and over) (Finch 1998) adults (19- 64 years) (Henderson 2002), school children (4-18 years) (Gregory 2000) and toddlers (11/2 - 41/2 years)(Gregory 1995)) surveys. (Table 7). High level consumer based estimates are taken as the $97.5 \%$ percentile (Table 8). Other calculations are illustrative and based on multiple consumption of single analytes contained in individual samples from Table 4 (Table 9).

\section{Results}

In almost three quarters of the samples, including all those of meat other than offal, none of the chemicals was observed above the limit of detection. PFOS was the chemical detected most often, especially in fish, shellfish, liver and kidney, and usually at the highest concentrations. 75 of the food samples contained trace levels of PFOS and other PFCs just above the reporting level of $1 \mu \mathrm{g} / \mathrm{kg}$. All of the listed eleven perfluoro analytes were found to be present across these food samples. All of the foods found to contain concentrations exceeding the limit of detection have been reported individually, by analyte in descending order of the summed concentration of the individual PFCs ( $\Sigma$ PFCs) of 1-63 $\mu \mathrm{g} / \mathrm{kg}$ (Tables 4-6). The highest concentrations 
were found in samples of smoked eel and whitebait. PFOSA was the next most frequently detected chemical, but only in certain fish species and crab. PFOA was detected at low concentrations in some samples of whitebait, crab and liver. The other chemicals analysed were detected only occasionally and at low concentrations, but no chemical was absent from and totally undetected in all of the samples. A summary table of the results for all 252 samples, arranged by sample type, illustrates the frequency, range and mean levels of contamination (Table 1). The highest individual concentrations were of $59 \mu \mathrm{g} / \mathrm{kg}$ of perfluorooctanesulphonic acid (PFOS) and $63 \mu \mathrm{g} / \mathrm{kg}$ total PFCs ( $\Sigma$ PFCs) in an eel sample, and $40 \mu \mathrm{g} / \mathrm{kg}$ PFOS (62 $\Sigma$ PFCs) in a whitebait sample. There were 6 samples with $\Sigma$ PFCs $>15 \mu \mathrm{g} / \mathrm{kg}$ (fish \& crustaceans), a further 7 samples with $\Sigma$ PFCs in the range 11-15 $\mu \mathrm{g} / \mathrm{kg}$ (including a liver), nine with $\Sigma$ PFCs in the range 6-10 $\mu \mathrm{g} / \mathrm{kg}$ (fish and livers), 31 with $\Sigma$ PFCs in the range $2-5 \mu \mathrm{g} / \mathrm{kg}$ (including kidneys, popcorn and processed peas) and 22 with $\Sigma$ PFCs at the reporting level of $1 \mu \mathrm{g} / \mathrm{kg}$ (including eggs and potatoes).

A set of representative chromatograms for one of the PFOS determinations is given (Figure 2). It was noted in separate LC-TOF experiments that PFOS $[\mathrm{M}-\mathrm{H}]^{-} \mathrm{m} / \mathrm{z}$ 498.927 can be readily distinguished from the isobaric interferences. These have a profile $m / z, 498.289,499.289$ and 500.289 which, within the constraint of containing a sulphonate grouping (MRM 499>80), gave a single fit $[\mathrm{M}-\mathrm{H}]^{-}$formulae of $\mathrm{C}_{26} \mathrm{H}_{44} \mathrm{NO}_{6} \mathrm{~S}$, taurodeoxycholic acid, with the first natural abundance isotope peak $[\mathrm{M}+1,-\mathrm{H}]^{-} \mathrm{m} / \mathrm{z} 499.289$ being the actual interfering ion. As there is a set of largely indistinguishable di-hydroxycholate epimers about the $\mathrm{C}_{3}, \mathrm{C}_{6}, \mathrm{C}_{7}, \mathrm{C}_{12}$ positions, the actual interferences in the various foods differ between samples as do bile salts between the various mammalian, fish and avian sources. As the di-hydroxycholate epimers in foods are secondary metabolites, there is as yet no clear relationship between the primary bile salts in a species and the observed interferences.

The highest positive results were all in the fish and offal food groups, as anticipated. Other primary produce foods, such as shellfish, meat, milk, butter, cheese, cereals and vegetables, were essentially free from contamination (Table 1). There was no observable trend in farming and husbandry practices; free range, organic, farmed and wild foods were all indistinguishable by PFC content. 


\section{Discussion}

Analytical methods

The analytical method has been validated previously (Lloyd 2009) and performed satisfactorily, with all samples being analysed to meet the required reporting level (RL) (Tables 1-2). The method proved reproducible and accurate over the course of this survey as determined by repeat analysis of in-house reference food samples (Table 3).

\section{Intake estimates}

Making the assumptions that these retail food samples reflect the general diet in the UK, it can be assumed that the latter is low in PFC. Dietary intakes of PFOS, PFOA and PFOSA were estimated from the results of this survey using food consumption data from various dietary surveys, in which the food eaten by each of up to 1,724 individual consumers was recorded over a 4- or 7-day period (Gregory 1995, Gregory 2000, Finch 1998, Henderson 2002). Average concentrations of the chemicals found in the oily fish, white fish, shellfish, liver, kidney, meat, milk and milk products, cereals, popcorn, jams, potatoes and vegetables samples were applied to all samples of the relevant food type. These dietary intakes do not take account of food types that were not included in the survey, nor of carp for which there were no recorded consumers in any of the dietary surveys. Adults were assumed to have a body weight of $60 \mathrm{~kg}$. For the other age groups the individual bodyweights of each recorded consumer were used.

The dietary intakes so estimated are presented in Table 7 for consumers in different age groups. These intakes are consumer rather than population intakes, as nonconsumers of a given food type are ignored in calculating the average figures. The numbers of recorded consumers of the oily fish species containing the highest concentrations, and of offal are relatively low in all age groups which, when combined with the relatively high concentrations in these food types, inflate the consumer intakes from those food types. However, because foods bread, milk and potatoes, all of which are consumed by nearly all the UK population were also 
included, the overall intakes shown in Table 7 also apply to the whole population. The estimated upper bound average adult dietary intakes of PFOS and PFOA 0.01 and $0.01 \mu \mathrm{g} / \mathrm{kg}$ bodyweight/day respectively (Table 7) are within the Tolerable Daily Intakes for these chemicals ( 0.15 and $1.5 \mu \mathrm{g} / \mathrm{kg}$ bodyweight/day respectively) set by the European Food Safety Authority (European Food Safety Authority, 2008), as are the corresponding high level (97.5 percentile) adult intakes of 0.02 and $0.02 \mu \mathrm{g} / \mathrm{kg}$ body weight/day respectively (Table 8 ).

An alternative method of estimating the dietary intakes of consumers of oily fish is to add the dietary intakes from typical portions of this food to that for the rest of the diet. This method allows for more robust intake estimates from oily fish species for which there were very few or no recorded consumers, e.g. eel, whitebait and carp. The Agency advises that all consumers should eat two portions of fish, one of which should be oily, as part of a balanced diet; that girls and women who may have children should not eat more than two portions of oily fish per week; and that boys, men and women who will not have children should not eat more than four portions of oily fish per week (Scientific Advisory Committee on Nutrition and Committee on Toxicity of Chemicals in Food, Consumer Products and the Environment 2004, Food Standards Agency 2004). A man who ate four $70 \mathrm{~g}$ portions of consistently the most contaminated oily fish in the survey (i.e. smoked eel, $59 \mu \mathrm{g} / \mathrm{kg}$ ) per week combined with average consumption of the rest of the diet (i.e. excluding the normal contribution from fish) would have a PFOS intake of $0.050 \mu \mathrm{g} / \mathrm{kg}$ bodyweight/day, which is again within the TDI (Table 9).

The concentrations of PFOS and PFOA in fish were consistent with those reported by other countries (Senthilkumar 2007, de Voogt 2008, Nania 2009). The predominance of PFOS accords with evidence that pefluoroalkyl sulphonates such as PFOS are more bioaccumulative than perfluoroalkanoic acids, such as PFOA, with the same fluorinated carbon chain length (Condor 2008). The concentrations found suggest that, if regulatory limits were to be considered, these might be appropriate only for PFOS in fish and animal liver, Limits are not likely to be needed in other foods, or at all for PFOA. However, the results of this survey do not indicate a need for increased consumer protection. 
Accurate quantification of PFCs at concentrations below $1 \mu \mathrm{g} / \mathrm{kg}$ in food, while feasible, is complex and costly (Lloyd 2009). It is clear from the results and the intake estimates, that it was possible to demonstrate that exposure to PFOS and PFOA would be considerably below the respective TDIs even for the highest consumers working to an LOD of $1 \mu \mathrm{g} / \mathrm{kg}$. On this basis, the analytical method described and used in this paper to generate the intake estimates was fit-for-purpose. The lower bound estimate for PFOS dietary intake in the UK of $1 \mathrm{ng} / \mathrm{kg} /$ day as estimated from the results of this study, was calculated as a consumer rather than population based estimate, which gave a higher result, but this is still comparable to estimates calculated for Spain $1 \mathrm{ng} / \mathrm{kg} /$ day (Ericson 2008), Ireland $1 \mathrm{ng} / \mathrm{kg} / \mathrm{day}$ (Clarke in press), Germany 2 ng/kg bw/day (Fromme), and Canada (4 ng/kg bw/day Tittlemier 2007).

\section{Conclusions}

The results from this study indicate an extremely low level of contamination in the English food chain, and they are directly comparable to the findings in other countries that have conducted similar studies. It would therefore be unlikely for any consumer, even an extreme consumer of the more contaminated foods, to exceed the TDI for PFOS or PFOA.

\section{Acknowledgments}

The authors would like to thank Ventress Technical Ltd for their assistance in preparing the sampling plan and for obtaining the samples. This work was funded by the UK Food Standards Agency. 
References

3M Company, 2003. Analysis of PFOS, FOSA and PFOA From Various Food Matrices Using HPLC Electrospray Mass Spectrometry. Analytical Report, June 21, 2001.

Berger, U., Holmström, K., Glynn, A., Berglund, M., Ankarberg, E., and Törnkvist, A. 2007. Perfluorinated alkyl substances in market basket food samples and fish from Lake Vättern and the Baltic Sea. Rapport till Naturvårdsverket Programområde Miljögiftssamordning Överenskommelse nr 2190641 Dnr: 721-5953-06Mm. Stockholm/Uppsala 2007-04-03.

Brooke, D., Footitt, T. A., and Nwaogu, T.A. 2004, Environmental risk evaluation report: Perfluoroctanesulphonate (PFOS) Draft report prepared for the UK Environment Agency. By Building Research Establishment, Watford, and Risk and Policy Analysts, Loddon, Norfolk. http://www.environmentagency.gov.uk/commondata/105385/pfos_rer_sept04_864557.pdf

Clarke, D. B., A., Lloyd, A. S., and Hird, S., 2008. Dietary intake estimate for perfluorooctanesulphonic acid (PFOS) and perfluorocompounds (PFCs) in Irish retail foods following determinations using standard addition LC-MS/MS. Food Additives and Contaminants, In preparation.

Conder, J. M., Hoke, R. A., De Wolf, W., Russell, M. H., and Buck R. C. 2008. Are PFCAs bioaccumulative? A critical review and comparison with regulatory criteria and persistent lipophilic compounds. Environ. Sci. Technol.; 42, 995-1003.

EFSA, 2008. Opinion of the Scientific Panel on Contaminants in the Food chain on Perfluorooctane sulphonate (PFOS), perfluorooctanoic acid (PFOA) and their salts. The EFSA Journal, 653, 1-131.

Ericson, I. Marti-Cid, R., Nadal, M., Van Bavel, B., Lindstrom, G., and Domingo, J. L., 2008. Human exposure to perfluorinated chemicals through the diet; intake of perfluorinated compounds in foods from the Catalan (Spain) market. J. Ag. Food Chem., 56, 1787-1794.

European Food Safety Authority, 2008. Perfluorooctane sulphonate (PFOS), perfluorooctanoic acid (PFOA) and their salts. Scientific Opinion of the Panel on Contaminants in the Food Chain, available at http://www.efsa.europa.eu/cs/BlobServer/Scientific_Opinion/contam_ej_653_PFOS PFOA_en.pdf?ssbinary=true. 
Food Standards Agency Fluorinated chemicals. UK dietary intakes. Food Survey Information Sheet, 2006; 11/06 available at www.food.gov.uk/multimedia/pdfs/fsis1106.pdf.

Finch, S., Doyle, W., Lowe, C., Bates, C. J., Prentice, A., Smithers, G. and Clarke, P. C., 1998. National Diet and Nutrition Survey: People aged 65 years and over. Volume 1: Report of the diet and dutrition survey. The Stationery Office.

Food Standards Agency, 2004. Fish and shellfish, available at http://www.eatwell.gov.uk/healthydiet/nutritionessentials/fishandshellfish/?lang=en.

Fromme, H., Schlummer, M., Möller, A., Gruber, L., Wolz, G., Ungewiss, J., Böhmer, S., Dekant, W., Mayer, R., Liebl, B., and Twardella, D., 2007. Exposure of an Adult Population to Perfluorinated Substances Using Duplicate Diet Portions and Biomonitoring Data. Environ. Sci. \& Technol., 41 (22), 7928 -7933.

Gregory, J., Lowe, S., Bates, C. J., Prentice, A., Jackson, L. V., Smithers, G., Wenlock, R, and Farron, M. National Diet and Nutrition Survey: young people aged 4-18 years. Volume 1: report of the diet and nutrition survey 2000. The Stationery Office, London.

Gregory, J., Collins, D. L., Davies, P. S. W., Hughes, J. M,. and Clarke, P. C. National Diet and Nutrition Survey: children aged 11/2 to 41/2 years. Volume 1: report of the diet and nutrition survey 1995. HMSO, London.

Guruge, K. S., Manage, P. M., Yamanaka, N., Miyazaki, S., Taniyasu, S., and Yamashita, N., 2008. Species-specific concentration of perfluoroalkyl contaminants in farm and pet animals in Japan. Chemosphere, 73, S210-S215.

Henderson, L., Gregory, J., and Swan, G. The National Diet and Nutrition Survey: adults aged 19 to 64 years. Volume 1: Types and quantities of foods consumed 2002. The Stationery Office, London.

Holmstrom, K. E., Jarnberg, U., and Bignert, A., 2005. Temporal trends of PFOS and PFOA in guillemot eggs from the Baltic sea, 1968-2003. Environ. Sci. \& Tech., 39(1), 80-84.

Jensen, A. A., and Leffers, H., 2008. Emerging endocrine disruptors. International Journal of Andrology, 31, 161-169.

Jin, Y., Saito, N., Harada, K., Inoue, K., and Koizumi, A., 2007. Historical Trends in Human Serum Levels of Perfluorooctanoate and Perfluorooctane Sulfonate in Shenyang, China. Tohuku J. Exp Med., 212, 63-70. 
Lloyd, A. S., Bailey, V. A., Hird, S., Routledge, A., Clarke, D. B., 2009. Mass spectral studies towards more reliable measurement of perfluorooctanesulfonic acid and other perfluorinated chemicals (PFCs) in food matrices using liquid chromatography/tandem mass spectrometry. Rapid Commun. Mass Spectrom., 23, 2923-2938.Nania, V., Pellegrini, G.E., Fabrizi, L., Sesta, G., de Sanctis, P., Luchetti, D., Pasquale, M.D., and Coni, E., 2009. Monitoring of perfluorinated compounds in edible fish from the Mediterranean sea. Food Chem., 115, 951-957.

Olsen, G. W., Mair, D. C., Church, T. R., Ellefson, M. E., Reagen, W. K., Boyd, T. M., Herron, R. M., Medhdizadehkashi, Z., Nobiletti, J. B., Rios, J. A., Butenhoff, J. L., and Zobel L. R., 2008. Decline in Perfluorooctanesulfonate and Other Polyfluoroalkyl Chemicals in American Red Cross Adult Blood Donors, 2000-2006. Environ. Sci. \& Technol., 42(13), 4989-4995.

Prevedouros, K., Cousins, I. T., Buck, R. C., and Korzeniowski, S. H., 2006. Sources, fate and transport of perfluorocarboxylates. Environ. Sci. \& Tech., 240(1), 32-44.

Senthilkumar, K., Ohi, E., Sajwan, K., Takasuga, T., and Kannan K. 2007.

Perfluorinated compounds in river water, river sediment, market fish, and wildlife samples from Japan. Bull. Environ. Contam. Toxicol., 79, 427-431.

Scientific Advisory Committee on Nutrition and Committee on Toxicity of Chemicals in Food, Consumer Products and the Environment, 2004 Advice on fish consumption: benefits \& risks. The Stationery Office, available at http://cot.food.gov.uk/pdfs/fishreport2004full.pdf.

So, M. K., Taniyasu, S., Lam, P. K. S., Zheng, G. J., Giesy, J. P., and Yamashita, N. A, 2006. Alkaline digestion and solid phase extraction methods for perfluorinated compounds in mussels and oysters from South China and Japan. Arch. Environ. Contam. Toxicol., 50, 240-248.

Spliethoff, H. M., Tao, L., Shaver, S. M., Aldous, K. M., Pass, K. A., Kannan, K., and Eadon, G. A., 2008. Use of Newborn Screening Program Blood Spots for Exposure Assessment: Declining Levels of Perfluorinated Compounds in New York State Infants. Environ. Sci. \& Technol., 42(14), 5361-5367.

Taniyasu, S., Kannan, K., So, M. K., Gulkowska, A., Sinclair, E., Okazawa, T., and Yamashita, N. A, 2005. Analysis of fluorotelomer alcohols, fluorotelomer acids, and short- and long-chain perfluorinated acids in water and biota. J Chrom A., 1093, 8997. 
Tittlemier, S. A., Pepper, K., Seymour, C., Moisey, J., Bronson, R., Cao, X.-L., and Dabeka, R. W., 2007. Dietary exposure of Canadians to perfluorinated carboxylates and perfluorooctane sulfonate via consumption of meat, fish, fast foods, and food items prepared in their packaging. J. Ag. Food Chem., 55, 3203-3210. de Voogt, P., van der Wielen, F. W. M., Westerveld, J., D’Hollander, W. and Bervoets, L., 2008. Determination of perfluorinated organic compounds in food and dust. Organohal. Comp., 70, 714-717.

Wang, Y., Yeung, L. W., Yamashita, N., Taniyasu, S., So, M. K., Murphy, M. B., and Lam P. K., 2008. Perfluorooctane sulfonate (PFOS) and related fluorochemicals in chicken egg in China. Chinese Science Bulletin, 53(4), 501-507. 
Table 1. Summary of the levels of PFCs by food type.

\begin{tabular}{|c|c|c|c|c|c|c|}
\hline Class & Type & $\mathbf{N}$ & $\begin{array}{c}\text { Range } \\
\Sigma \text { PFCs } \mu \mathrm{g} / \mathrm{kg}\end{array}$ & $\mathbf{N} \geq \mathbf{L O Q}$ & Mean & $\%$ Positive \\
\hline \multirow[t]{13}{*}{ Fish } & Whitebait & 6 & $8-62$ & 6 & 28 & 100 \\
\hline & Eel & 6 & $<1-63$ & 3 & 11 & 50 \\
\hline & Carp & 6 & $<1-8$ & 5 & 5 & 83 \\
\hline & Sprats & 3 & $3-8$ & 3 & 5 & 100 \\
\hline & Sardines & 6 & $1-7$ & 6 & 4 & 100 \\
\hline & Cod & 4 & $<0-4$ & 2 & 2 & 50 \\
\hline & Mackerel & 4 & $<1-3$ & 2 & 2 & 50 \\
\hline & Haddock & 4 & $<1-3$ & 3 & 1 & 75 \\
\hline & Trout & 4 & $<1-1$ & 2 & $<1$ & 50 \\
\hline & Herring & 4 & $<1-2$ & 1 & $<1$ & 25 \\
\hline & Plaice & 2 & $<1-1$ & 1 & $<1$ & 50 \\
\hline & Salmon & 8 & $<1$ & 0 & $<1$ & 0 \\
\hline & Sole & 2 & $<1$ & 0 & $<1$ & 0 \\
\hline Shellfish & Oysters & 2 & $1-1$ & 1 & $<1$ & 50 \\
\hline \multirow[t]{4}{*}{ Crustaceans } & Crab & 6 & $11-20$ & 6 & 16 & 100 \\
\hline & Crayfish & 1 & 2 & 1 & 2 & 100 \\
\hline & Prawns & 2 & $<1-1$ & 1 & 1 & 50 \\
\hline & Langoustine & 1 & $<1$ & 0 & $<1$ & 0 \\
\hline \multirow[t]{3}{*}{ Offal } & Liver & 25 & $<1-14$ & 19 & 2 & 76 \\
\hline & Kidney & 12 & $<1-3$ & 8 & 1 & 75 \\
\hline & Other offal & 4 & $<1$ & 0 & $<1$ & 0 \\
\hline Meat & Carcass meat & 16 & $<1$ & 0 & $<1$ & 0 \\
\hline \multirow[t]{2}{*}{ Dairy } & Milk & 11 & $<1$ & 0 & $<1$ & 0 \\
\hline & Cheese & 10 & $<1$ & 0 & $<1$ & 0 \\
\hline \multirow[t]{2}{*}{ Eggs } & Chicken & 10 & $<1-1$ & 1 & $<1$ & 10 \\
\hline & Duck & 2 & $<1$ & 0 & $<1$ & 0 \\
\hline \multirow[t]{2}{*}{ Oils } & Fish & 4 & $<1$ & 0 & $<1$ & 0 \\
\hline & Vegetable & 6 & $<1$ & 0 & $<1$ & 0 \\
\hline \multirow[t]{3}{*}{ Plant produce } & Grains/bread & 12 & $<1-1$ & 2 & $<1$ & 17 \\
\hline & Vegetables & 63 & $<1-2$ & 2 & $<1$ & 3 \\
\hline & Fruit/jam & 6 & $<1$ & 0 & $<1$ & 0 \\
\hline
\end{tabular}

Range $\Sigma$ PFCs $=$ the lowest and highest values of the combined concentration of all 11 Individual fluorinated analytes. Mean $=$ lower bound, $<$ LOD $=0$

$\mathrm{N}=$ The number of samples analysed in each group.

$\mathrm{N} \geq \mathrm{LOQ}=$ The number of samples where residues were measured.

Meat $=$ pork, lamb, beef, venison, chicken, turkey. 
Table 2. Summary of MRM transitions, retention time, solvent based and matrix based LODs

\begin{tabular}{|c|c|c|c|c|c|c|c|c|c|c|}
\hline \multirow[b]{2}{*}{ Test analyte } & \multicolumn{2}{|c|}{ Primary Ions } & \multicolumn{2}{|c|}{ Qualifier Ions } & \multicolumn{2}{|c|}{$\mathrm{MeOH}$ LODs } & \multicolumn{4}{|c|}{ Matrix based LODs $\mu \mathrm{g} / \mathrm{kg}^{\mathrm{b}}$} \\
\hline & Transition & Product ion & Transition & Product ion & $\mathrm{Rt}$ & $\mu \mathrm{g} / \mathrm{kg}^{\mathrm{a}}$ & Milk & Jam & Veg Oil & Salmon \\
\hline PFHxA & $313.1>269.1$ & {$\left[\mathrm{C}_{5} \mathrm{~F}_{11}\right]^{-}$} & $313.1>119.1$ & {$\left[\mathrm{C}_{2} \mathrm{~F}_{5}\right]^{-}$} & 11.25 & 0.01 & 0.025 & 0.1 & 0.05 & 0.3 \\
\hline PFHpA & $363.1>319.1$ & {$\left[\mathrm{C}_{6} \mathrm{~F}_{13}\right]^{-}$} & $363.1>169.1$ & {$\left[\mathrm{C}_{3} \mathrm{~F}_{7}\right]^{-}$} & 11.92 & 0.005 & 0.01 & 0.05 & 0.02 & 0.01 \\
\hline PFOA & $413.1>369.1$ & {$\left[\mathrm{C}_{7} \mathrm{~F}_{15}\right]^{-}$} & $413.1>169.1$ & {$\left[\mathrm{C}_{3} \mathrm{~F}_{7}\right]^{-}$} & 12.43 & 0.005 & 0.025 & 0.01 & 0.05 & 0.01 \\
\hline PFNA & $463.1>419.1$ & {$\left[\mathrm{C}_{8} \mathrm{~F}_{17}\right]^{-}$} & $463.1>219.1$ & {$\left[\mathrm{C}_{4} \mathrm{~F}_{9}\right]^{-}$} & 12.86 & 0.001 & 0.05 & 0.02 & 0.05 & 0.02 \\
\hline PFDeA & $513.1>469.1$ & {$\left[\mathrm{C}_{9} \mathrm{~F}_{19}\right]^{-}$} & $513.1>219.1$ & {$\left[\mathrm{C}_{4} \mathrm{~F}_{9}\right]^{-}$} & 13.26 & 0.001 & 0.025 & 0.02 & 0.02 & 0.05 \\
\hline PFUnA & $563.1>519.1$ & {$\left[\mathrm{C}_{10} \mathrm{~F}_{21}\right]^{-}$} & $563.1>319.1$ & {$\left[\mathrm{C}_{6} \mathrm{~F}_{13}\right]^{-}$} & 13.66 & 0.001 & 0.025 & 0.02 & 0.01 & 0.02 \\
\hline PFDoA & $613.1>569.1$ & $\left.\left[\mathrm{C}_{12} \mathrm{~F}_{23}\right]\right]^{-}$ & $613.1>269.1$ & {$\left[\mathrm{C}_{5} \mathrm{~F}_{11}\right]^{-}$} & 14.02 & 0.001 & 0.025 & 0.02 & 0.02 & 0.05 \\
\hline PFBSH & $299.1>80.1$ & {$\left[\mathrm{SO}_{3}\right]^{-}$} & $299.1>99.1$ & {$\left[\mathrm{SO}_{3} \mathrm{~F}\right]^{-}$} & 10.05 & 0.01 & 0.05 & 0.05 & 0.01 & 0.05 \\
\hline PFHxS & $399.1>80.1$ & {$\left[\mathrm{SO}_{3}\right]^{-}$} & $399.1>99.1$ & {$\left[\mathrm{SO}_{3} \mathrm{~F}\right]^{-}$} & 11.64 & 0.01 & 0.05 & 0.02 & 0.05 & 0.1 \\
\hline PFOS & $499.1>80.1$ & {$\left[\mathrm{SO}_{3}\right]^{-}$} & $499.1>99.1$ & {$\left[\mathrm{SO}_{3} \mathrm{~F}\right]^{-}$} & 12.59 & 0.01 & 0.1 & 0.1 & 0.05 & 0.1 \\
\hline PFOSA & $498.1>78.0$ & {$\left[\mathrm{SNO}_{2}\right]^{-}$} & $498.1>169.1$ & {$\left[\mathrm{C}_{3} \mathrm{~F}_{7}\right]^{-}$} & 13.96 & 0.002 & 0.025 & 0.02 & 0.1 & 1 \\
\hline THPFOS & $427.1>407.1$ & {$[\mathrm{M}-\mathrm{HF}]^{-}$} & - & - & 12.34 & - & - & - & - & - \\
\hline${ }^{13} \mathrm{C}_{2}$-PFDeA & $515.1>470.1$ & {$\left[{ }^{12} \mathrm{C}_{8}{ }^{13} \mathrm{C}_{2} \mathrm{~F}_{19}\right]^{-}$} & - & - & 13.26 & - & - & - & - & - \\
\hline${ }^{13} \mathrm{C}_{4}$-PFOA & $417.1>372.1$ & {$\left[{ }^{12} \mathrm{C}_{4}{ }^{13} \mathrm{C}_{3} \mathrm{~F}_{15}\right]^{-}$} & - & - & 12.42 & . & - & - & - & - \\
\hline${ }^{13} \mathrm{C}_{4}$-PFOS & $503.1>80.1$ & {$\left[\mathrm{SO}_{3}\right]^{-}$} & - & - & 12.57 & & - & - & - & - \\
\hline $\mathrm{D}_{9}-n$-Et-FOSE & $639.1>45.0$ & {$\left[\mathrm{HCO}_{2}\right]^{-}$} & - & - & 14.81 & & - & - & - & - \\
\hline
\end{tabular}

Summary of MRM transitions, retention times and solvent based Limits of Determination LODs of PFC analytical standards. ${ }^{a}$ Methanol based LODs $(3 \mathrm{x}$ S/N) were all $<10 \mathrm{ng} / \mathrm{kg}(0.25 \mathrm{ng} / \mathrm{ml})$.

${ }^{\mathrm{b}}$ Concentrations expressed as $\mu \mathrm{g} / \mathrm{kg}$ food equivalent, matrix matched. $10 \mathrm{~g}$ food matrix concentrated in the extract 25-fold. $\mathrm{D}_{9}$ - $n$-Et-FOSE

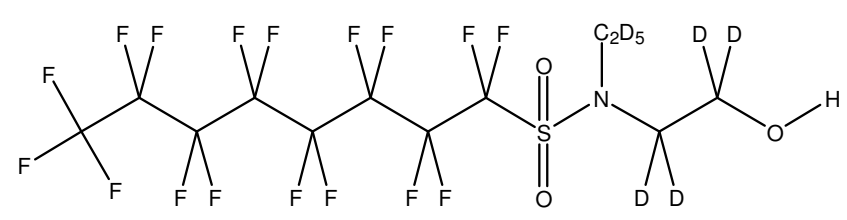

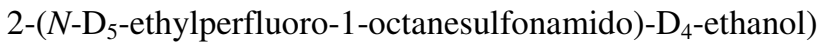

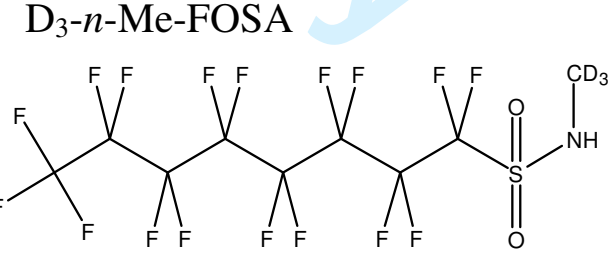

$\mathrm{N}$-D $\mathrm{D}_{3}$-methylperfluoro-1-octanesulfonamide 
Table 3. Interbatch reproducibility data for repeat analysis of food sample contaminated with PFCs.

\begin{tabular}{|c|c|c|c|c|c|c|c|c|c|c|c|}
\hline \multirow[b]{2}{*}{ Sample } & \multicolumn{7}{|c|}{ Measured PFC concentration $\mu \mathrm{g} / \mathrm{kg}$} & \multirow[b]{2}{*}{ PFDeA } & \multirow[b]{2}{*}{ PFUnA } & \multirow[b]{2}{*}{ PFDoA } & \multirow[b]{2}{*}{ PFOSA } \\
\hline & PFBS & PFHxS & PFOS & PFHxA & PFHpA & PFOA & PFNA & & & & \\
\hline Mackerel & & $\sqrt{3}$ & $1[2]$ & & & & & & & & $1[1]$ \\
\hline Dressed crab & & & $6[4]$ & & & $9[8]$ & $1[2]$ & & & & $1[1]$ \\
\hline Whitebait & & & $11[15]$ & & & & & & & & $10[27]$ \\
\hline Whitebait & & & $12[9]$ & & & & & & & & $6[4]$ \\
\hline Whitebait & & & $48[40]$ & & & $4[5]$ & & & $1[2]$ & & \\
\hline Cromer crab & & $1[1]$ & $14[12]$ & & & $4[4]$ & $2[1]$ & $1[1]$ & & & $1[2]$ \\
\hline Spider crab & & $2[1]$ & $13[9]$ & & & $5[6]$ & & & & & \\
\hline Wild roe deer liver & & & $10[11]$ & & & $3[6]$ & $1[2]$ & & & & \\
\hline Carp roe & & & $765[757]$ & & & & & & & & \\
\hline
\end{tabular}

Interbatch reproducibility data for repeat analysis of naturally incurred PFC containing food sample.

Results for the second determination are presented in parenthesis. 
Table 4. Individual concentrations of PFCs in each food sample.

\begin{tabular}{|c|c|c|c|c|c|c|c|c|c|c|c|c|c|}
\hline & \multirow[b]{2}{*}{ Sample } & \multicolumn{12}{|c|}{ Measured PFC concentration $\mu \mathrm{g} / \mathrm{kg}$} \\
\hline & & PFHxA & PFHpA & PFOA & PFNA & PFDeA & PFUnA & PFDoA & PFBS & PFHxS & PFOS & PFOSA & $\Sigma \mathrm{PFCs}$ \\
\hline 1 & Smoked Eel & $<1$ & $<1$ & $<1$ & $<1$ & 2 & 2 & $<1$ & $<1$ & $<1$ & 59 & $<1$ & 63 \\
\hline 2 & Whitebait & $<1$ & $<1$ & 5 & $<1$ & $<1$ & 2 & $<1$ & $<1$ & 1 & 40 & 14 & 62 \\
\hline 3 & Whitebait & 7 & $<1$ & $<1$ & $<1$ & $<1$ & $<1$ & $<1$ & $<1$ & $<1$ & 15 & 27 & 49 \\
\hline 4 & Cromer crab (dressed) & $<1$ & $<1$ & 4 & 1 & $<1$ & 1 & $<1$ & $<1$ & 2 & 12 & $<1$ & 20 \\
\hline 5 & Spider crab (whole) & $<1$ & $<1$ & 6 & 1 & $<1$ & $<1$ & $<1$ & $<1$ & $<1$ & 13 & $<1$ & 20 \\
\hline 6 & Whitebait & $<1$ & $<1$ & $<1$ & $<1$ & $<1$ & $<1$ & $<1$ & $<1$ & $<1$ & 9 & 7 & 16 \\
\hline 7 & Whitebait & $<1$ & $<1$ & $<1$ & $<1$ & $<1$ & $<1$ & $<1$ & $<1$ & $<1$ & 9 & 6 & 15 \\
\hline 8 & Dressed Crab & $<1$ & $<1$ & 8 & 2 & $<1$ & $<1$ & $<1$ & $<1$ & $<1$ & 4 & 1 & 15 \\
\hline 9 & Brown crab (whole) & $<1$ & $<1$ & 6 & 3 & $<1$ & $<1$ & $<1$ & $<1$ & $<1$ & 3 & 2 & 14 \\
\hline 10 & Wild roe deer liver & $<1$ & $<1$ & 3 & 1 & $<1$ & $<1$ & $<1$ & $<1$ & $<1$ & 10 & $<1$ & 14 \\
\hline 11 & Whitebait & $<1$ & $<1$ & $<1$ & $<1$ & $<1$ & $<1$ & $<1$ & $<1$ & $<1$ & 9 & 4 & 13 \\
\hline 12 & Crab (whole) & $<1$ & $<1$ & 5 & 1 & $<1$ & 1 & 1 & $<1$ & $<1$ & 2 & 3 & 13 \\
\hline 13 & Dressed Crab & $<1$ & $<1$ & 4 & 1 & $<1$ & $<1$ & $<1$ & $<1$ & $<1$ & 4 & 2 & 11 \\
\hline 14 & Mirror carp & $<1$ & $<1$ & $<1$ & $<1$ & $<1$ & $<1$ & $<1$ & $<1$ & $<1$ & 8 & $<1$ & 8 \\
\hline 15 & Frozen sprats & $<1$ & $<1$ & $<1$ & $<1$ & $<1$ & $<1$ & $<1$ & $<1$ & $<1$ & 4 & 4 & 8 \\
\hline 16 & Whitebait & $<1$ & $<1$ & $<1$ & $<1$ & $<1$ & $<1$ & $<1$ & $<1$ & $<1$ & 5 & 3 & 8 \\
\hline 17 & Carp & $<1$ & $<1$ & $<1$ & $<1$ & $<1$ & $<1$ & $<1$ & $<1$ & $<1$ & 8 & $<1$ & 8 \\
\hline 18 & Sardines & $<1$ & $<1$ & $<1$ & $<1$ & $<1$ & 2 & $<1$ & $<1$ & $<1$ & 3 & 2 & 7 \\
\hline 19 & Venison Liver & $<1$ & $<1$ & $<1$ & $<1$ & $<1$ & $<1$ & $<1$ & $<1$ & $<1$ & 7 & $<1$ & 7 \\
\hline 20 & Fresh carp & $<1$ & $<1$ & $<1$ & $<1$ & $<1$ & $<1$ & $<1$ & $<1$ & $<1$ & 6 & $<1$ & 6 \\
\hline 21 & Common carp & $<1$ & $<1$ & $<1$ & $<1$ & $<1$ & $<1$ & $<1$ & $<1$ & $<1$ & 6 & $<1$ & 6 \\
\hline 22 & Pigs liver & $<1$ & $<1$ & 2 & $<1$ & $<1$ & $<1$ & $<1$ & $<1$ & $<1$ & 4 & $<1$ & 6 \\
\hline 23 & Sliced lamb liver & $<1$ & $<1$ & $<1$ & $<1$ & $<1$ & $<1$ & $<1$ & $<1$ & $<1$ & 5 & $<1$ & 5 \\
\hline 24 & Pigs kidney & $<1$ & $<1$ & 1 & $<1$ & $<1$ & $<1$ & $<1$ & $<1$ & $<1$ & 4 & $<1$ & 5 \\
\hline 25 & Sprats & $<1$ & $<1$ & $<1$ & $<1$ & $<1$ & $<1$ & $<1$ & $<1$ & $<1$ & 1 & 4 & 5 \\
\hline 26 & Cornish Sardines & $<1$ & $<1$ & $<1$ & $<1$ & $<1$ & $<1$ & $<1$ & $<1$ & $<1$ & 2 & 3 & 5 \\
\hline 27 & Ox Liver & $<1$ & $<1$ & $<1$ & $<1$ & $<1$ & $<1$ & $<1$ & $<1$ & $<1$ & 5 & $<1$ & 5 \\
\hline 28 & Carp & $<1$ & $<1$ & $<1$ & $<1$ & $<1$ & $<1$ & $<1$ & $<1$ & $<1$ & 4 & $<1$ & 4 \\
\hline 29 & Bideford cod & $<1$ & $<1$ & $<1$ & $<1$ & $<1$ & $<1$ & $<1$ & $<1$ & $<1$ & 2 & 2 & 4 \\
\hline 30 & Sardines & $<1$ & $<1$ & $<1$ & $<1$ & $<1$ & $<1$ & $<1$ & $<1$ & $<1$ & 3 & 1 & 4 \\
\hline 31 & Pork Liver & $<1$ & $<1$ & $<1$ & $<1$ & $<1$ & $<1$ & $<1$ & $<1$ & $<1$ & 4 & $<1$ & 4 \\
\hline 32 & Lambs Liver & $<1$ & $<1$ & $<1$ & $<1$ & $<1$ & $<1$ & $<1$ & $<1$ & $<1$ & 4 & $<1$ & 4 \\
\hline 33 & Sardines & $<1$ & $<1$ & $<1$ & $<1$ & $<1$ & $<1$ & $<1$ & $<1$ & $<1$ & 2 & 1 & 3 \\
\hline 34 & Beef liver & $<1$ & $<1$ & $<1$ & $<1$ & $<1$ & $<1$ & $<1$ & $<1$ & $<1$ & 3 & $<1$ & 3 \\
\hline 35 & Halal beef liver & $<1$ & $<1$ & $<1$ & $<1$ & $<1$ & $<1$ & $<1$ & $<1$ & $<1$ & 3 & $<1$ & 3 \\
\hline 36 & Lambs liver & $<1$ & $<1$ & $<1$ & $<1$ & $<1$ & $<1$ & $<1$ & $<1$ & $<1$ & 3 & $<1$ & 3 \\
\hline
\end{tabular}




\section{Food Additives and Contaminants}

English Sprats

Whole Herring

Mackerel

Whole Mackerel

Cornish Sardines

Ox Kidney

Farmed red deer liver

Lambs kidney

Wild English Eels

Cod

Crayfish

Lambs Liver

Lambs Liver

Lambs Liver

Ox Kidney

Marrowfat Peas

Toffee Popcorn

Haddock fillet

Haddock portions

Smoked eel

Herring

Cornish sardines

Ox liver

Wild venison liver

Beef kidney

Lambs kidney

R. Trout

Whole R. Trout

Plaice fillets

Haddock Fillets

N. Atlantic Prawns

Pacific Oysters

Pork Sliced Liver

Ox Liver

Organic pig kidney

Pig Kidney

Organic Free Range Eggs

Baby Potatoes [Maris Peer]

Sweet Pop Corn

\section{$<1<1<1<1<1<1$}

$3<1<1<1<1<1<1$

$<1$

$<1$

2

3

$2<1<1<1<1<1<1<1$

$<1<<<1<1<1<1<1<1$

$<1<1<1<1<1<1<1$

$\begin{array}{lllll}<1<1<1<1<1<1 & <1<1<1\end{array}$

$<1<1<1 \quad<1 \quad<1 \quad<1 \quad<1$

$\begin{array}{lllllll}<1<1 & <1 & <1 & <1 & <1 & <1\end{array}$

$<1<1<1<1<1<1<1$

$<1<1$

$<1<1$

$<1<1$

$<1$

$<1$

$<1<1<1<1$

$<1 \quad<1$

$\begin{array}{ll}<1 & <1 \\ <1 & <1\end{array}$

$<1<1$

$<1<$

$<1$

$<1$

$<1$

$<1<1<1<1$

$<1<1<1<1$

$<1$

$<1$

$<1$

$<1$

$<1$

$<1$

$<1$

$<1 \quad<1$

$<1<1$

$<1<1$

$<1<1$

$<1<1$

$<1<1$

$<1<1$

$<1<1$

$<1<1$

$<1 \quad 1$

$<1$

$<1$

$<1$

$<1$

$<1$

$<1$

$<1$

$<1$

$<1$

$<1$

$<1$

$<1$

$<$

$<1$

$\begin{array}{llll}<1 & <1 & <1 & <1 \\ <1 & <1 & <1 & <1\end{array}$

$\begin{array}{llll}<1 & <1 & <1 & <1 \\ <1 & <1 & <1 & <1\end{array}$

$<1<1<1<1$

$<1<1<1<1$

$<1<1<1<1<1<1$

$<1<1<1<1<1<1$

$<1<1<1<1<1<1$

$<1<1<1<1<1<1$

$<1<1$

$<1<1$

$<1$

$<1$

$<1$

$<1 \quad 1$

$<1<1$

$<1<1$

$<1$

2

$<1$
$<1$

$<1$

$<1$

$<1$

$<1$

$<1$

$<1$

$<1$

$<1$

$<1$

$<1$

$<1$

$<1$

$<1$
$<1$

$<1$

$<1$

$<1$

$<1$

$<1$

$<1$

$<1$

$<1$

$<1$

$\Sigma \mathrm{PFCs}=$ combined total concentration of all individual PFCs $=$ PFAS. 
Table 5. Concentrations ( $\mu \mathrm{g} / \mathrm{kg}$ fresh weight) of PFOS, PFOA, PFAS and PFOSA in fish and shellfish

\begin{tabular}{|c|c|c|c|c|c|c|c|c|c|c|}
\hline \multirow{2}{*}{$\begin{array}{l}\text { Species } \\
\text { (No of samples) }\end{array}$} & \multicolumn{2}{|c|}{ PFOS } & \multicolumn{2}{|c|}{ PFOA } & \multicolumn{2}{|c|}{ PFAS (lower bound) } & \multicolumn{2}{|c|}{ PFAS (upper bound) } & \multicolumn{2}{|c|}{ PFOSA } \\
\hline & Mean & Range & Mean & Range & Mean & Range & Mean & Range & Mean & Range \\
\hline Eel (fresh) (3) & 1.3 & $<1-2$ & $<1$ & - & 0.7 & $0-2$ & 11 & $11-12$ & $<1$ & - \\
\hline Eel (smoked) (3) & 20 & $<1-59$ & $<1$ & - & 21 & $0-63$ & 31 & $11-71$ & $<1$ & - \\
\hline Herring (4) & 1.0 & $<1-1$ & $<1$ & - & 1.0 & $0-3$ & 12 & $11-13$ & $<1$ & - \\
\hline Mackerel (4) & 1.2 & $<1-2$ & $<1$ & - & 1.5 & $0-3$ & 11 & $11-12$ & $<1$ & - \\
\hline Atlantic salmon (farmed) (5) & $<1$ & - & $<1$ & - & 0 & - & 11 & - & $<1$ & - \\
\hline Atlantic salmon (wild) (2) & $<1$ & - & $<1$ & - & 0 & - & 11 & - & $<1$ & - \\
\hline Alaskan salmon (wild) (1) & $<1$ & - & $<1$ & - & 0 & - & 11 & - & $<1$ & - \\
\hline Sardines (6) & 2.0 & $1-3$ & $<1$ & - & 5.5 & $1-7$ & 13 & $11-15$ & 2.2 & $1-3$ \\
\hline Sprats (3) & 3.0 & $1-4$ & $<1$ & - & 5.3 & $3-8$ & 14 & $12-17$ & 3.3 & $2-4$ \\
\hline Trout (farmed) (4) & 1.0 & $<1-1$ & $<1$ & - & 0.50 & $0-1$ & 11 & - & $<1$ & - \\
\hline Whitebait (6) & 15 & $<1-40$ & 1.3 & $<1-5$ & 28 & $8-62$ & 36 & $17-68$ & 10 & $1-27$ \\
\hline Carp (6) & 5.5 & $<1-8$ & $<1$ & - & 5.3 & $0-8$ & 16 & $11-18$ & $<1$ & - \\
\hline All oily fish (47) & 4.8 & $<1-59$ & 1.1 & - & 6.7 & $0-63$ & 17 & $11-71$ & 2.5 & $1-27$ \\
\hline $\operatorname{Cod}(4)$ & 1.5 & $<1-2$ & $<1$ & - & 1.5 & $0-4$ & 12 & $11-13$ & $<1$ & - \\
\hline Haddock (4) & 1.0 & $<1-1$ & $<1$ & - & 1.3 & $1-2$ & 11 & - & $<1$ & - \\
\hline Plaice(2) & 1.0 & $<1-1$ & $<1$ & - & 0.5 & $0-1$ & 11 & - & $<1$ & - \\
\hline Sole (2) & $<1$ & $<1-1$ & $<1$ & - & 0 & - & 11 & - & $<1$ & - \\
\hline All whitefish (12) & 1.2 & $<1-2$ & $<1$ & - & 0.8 & $0-4$ & 11 & 11-13 & 1.1 & 1-2 \\
\hline Crab (6) & 6.3 & $2-13$ & 5.5 & $4-8$ & 16 & $11-20$ & 22 & $18-28$ & 1.7 & $1-3$ \\
\hline Crayfish (1) & $<1$ & - & $<1$ & - & 2.0 & - & 12 & 12 & $<1$ & - \\
\hline Langoustine (1) & $<1$ & - & $<1$ & - & 1.0 & - & 11 & 11 & $<1$ & - \\
\hline Pacific oysters (2) & $2.5^{*}$ & $1-10 *$ & $<1$ & - & 0 & - & $17 *$ & $11-47 *$ & $<1$ & - \\
\hline Prawns (2) & $<1$ & $<1-1$ & $<1$ & - & 0.5 & $0-1$ & 11 & 11 & $<1$ & - \\
\hline All shellfish (12) & 4.4 & $1-13$ & 3.3 & $1-8$ & 8.2 & $0-20$ & 20 & $11-47$ & 1.3 & $1-3$ \\
\hline
\end{tabular}

Note: * Means and ranges affected by one or more higher than usual LODs. PFAS $=\Sigma$ PFCs. 
Table 6. Concentrations ( $\mu \mathrm{g} / \mathrm{kg}$ fresh weight) of PFOS, PFOA, PFAS and PFOSA in other foods

\begin{tabular}{|c|c|c|c|c|c|c|c|c|c|c|}
\hline \multirow{2}{*}{$\begin{array}{l}\text { Food } \\
\text { (No of samples) }\end{array}$} & \multicolumn{2}{|c|}{ PFOS } & \multicolumn{2}{|c|}{ PFOA } & \multicolumn{2}{|c|}{ PFAS (lower bound) } & \multicolumn{2}{|c|}{ PFAS (upper bound) } & \multicolumn{2}{|c|}{ PFOSA } \\
\hline & Mean $\dagger$ & Range & Mean $\dagger$ & Range & Mean & Range & Mean & Range & Mean $\dagger$ & Range \\
\hline Chicken liver (2) & $<1$ & - & $<1$ & - & 0 & - & 16 & 11,20 & $<1$ & - \\
\hline Chicken liver pate (1) & $<1$ & - & $<1$ & - & 0 & - & 11 & - & $<1$ & - \\
\hline Duck liver pate (1) & $<1$ & - & $<1$ & - & 0 & - & & & $<1$ & - \\
\hline Lambs' liver (7) & 2.6 & $<1-5$ & $<1$ & - & 2.6 & $0-5$ & 13 & $11-15$ & $<1$ & - \\
\hline Ox liver (5) & 1.8 & $<1-5$ & $<1$ & - & 1.4 & $0-5$ & 12 & $11-15$ & $<1$ & - \\
\hline Pigs' liver (5) & 2.2 & $<1-4$ & 1.2 & $1-2$ & 2.2 & $0-6$ & 12 & $11-15$ & $<1$ & - \\
\hline Venison liver (4) & 5.0 & $1-10$ & 1.5 & $1-3$ & 6.0 & $1-14$ & 16 & $11-22$ & $<1$ & - \\
\hline All liver (25) & 2.5 & $1-10$ & 1.1 & $1-3$ & 2.4 & $0-14$ & 13 & 11-22 & $<1$ & - \\
\hline Lambs' kidney (4) & 1.3 & $1-2$ & $<1$ & - & 0.8 & $0-2$ & 11 & $11-12$ & $<1$ & - \\
\hline Ox kidney (4) & 1.8 & $<1-3$ & $<1$ & - & 1.5 & $0-3$ & 12 & $11-13$ & $<1$ & - \\
\hline Pigs' kidney (4) & 1.6 & $<1-4$ & $<1$ & - & 0.7 & $0-1$ & 11 & - & $<1$ & - \\
\hline All kidney (12) & 1.4 & $1-3$ & $<1$ & - & 1.3 & $0-5$ & 12 & 11-14 & $<1$ & - \\
\hline Lambs' heart (2) & $<1$ & - & $<1$ & - & 0 & - & 11 & - & $<1$ & - \\
\hline Black pudding (2) & $<1$ & - & $<1$ & - & 0 & - & 11 & - & $<1$ & - \\
\hline Bread (4) & $<1$ & - & $<1$ & - & 0 & - & 11 & - & $<1$ & - \\
\hline Cereals (4) & $<1$ & - & $<1$ & - & 0 & - & 11 & - & $<1$ & - \\
\hline Popcorn (4) & $<1$ & - & $<1$ & - & 0.8 & $0-2$ & 11 & $11-12$ & $<1$ & - \\
\hline Cheese (10) & $<1.9^{*}$ & $<1-<10^{*}$ & $<1$ & - & 0 & - & $15^{*}$ & $11-47 *$ & $<1$ & - \\
\hline Milk (11) & $<1$ & - & $<1$ & - & 0 & - & 11 & $11-12$ & $<1$ & - \\
\hline Eggs (12) & $<1$ & $<1-1$ & $<1$ & - & 0.1 & $0-2$ & 11 & - & $<1$ & - \\
\hline Fish oil supplements (4) & $<1$ & - & $<1$ & - & 0 & - & 11 & - & $<1$ & - \\
\hline Vegetable oils (6) & $<1$ & - & $<1$ & - & 0 & - & 11 & - & $<1$ & - \\
\hline Jams (6) & $<1$ & - & $<1$ & - & 0 & - & 11 & - & $<1$ & - \\
\hline Meat (not offal) (16) & $<1$ & - & $<1$ & - & 0 & - & 11 & - & $<1$ & - \\
\hline Potatoes \& products $(21)$ & $<1$ & - & $<1$ & - & 0.1 & $0-1$ & 11 & - & $<1$ & - \\
\hline Vegetables (42) & $<1$ & - & $<1$ & - & 0.1 & $0-2$ & 11 & $11-12$ & $<1$ & - \\
\hline
\end{tabular}

Note: $†$ Upper bound values (where the value of the LOD is used in place of $<$ LOD)

Means and ranges affected by one or more higher than usual LODs. PFAS $=\Sigma$ PFCs. 
1 Table 7. Estimated average UK dietary intakes ( $\mu \mathrm{g} / \mathrm{kg}$ bodyweight/day) of fluorinated chemicals by consumers of different age ranges 2 from the diet in 2007-08 3

\begin{tabular}{|c|c|c|c|c|c|c|c|c|}
\hline \multirow[t]{3}{*}{ Food group } & \multicolumn{8}{|c|}{ Estimated average dietary exposure ( $\mu \mathrm{g} / \mathrm{kg}$ bodyweight/day) } \\
\hline & \multicolumn{2}{|c|}{ PFOS } & \multicolumn{2}{|c|}{ PFOA } & \multicolumn{2}{|c|}{ PFOSA } & \multicolumn{2}{|c|}{ PFAS } \\
\hline & Upper & Lower & Upper & Lower & Upper & Lower & Upper & Lower \\
\hline \multicolumn{9}{|l|}{ Senior citizens } \\
\hline - living at home & 0.009 & 0.0009 & 0.008 & $<0.00005$ & 0.008 & 0.0003 & 0.09 & 0.001 \\
\hline - in old peoples' homes & 0.008 & 0.0004 & 0.007 & $<0.00005$ & 0.007 & 0.0001 & 0.08 & 0.0007 \\
\hline Adults & 0.01 & 0.0001 & 0.01 & $<0.00005$ & 0.01 & 0.0004 & 0.1 & 0.002 \\
\hline \multicolumn{9}{|l|}{ Schoolchildren } \\
\hline -age $4-6$ years & 0.02 & 0.001 & 0.02 & $<0.00005$ & 0.02 & 0.0003 & 0.3 & 0.002 \\
\hline -age $7-10$ years & 0.02 & 0.0008 & 0.02 & $<0.00005$ & 0.02 & 0.0003 & 0.2 & 0.001 \\
\hline -age $11-14$ years & 0.01 & 0.0005 & 0.01 & $<0.00005$ & 0.01 & 0.0002 & 0.1 & 0.001 \\
\hline -age $15-18$ years & 0.01 & 0.0005 & 0.009 & $<0.00005$ & 0.009 & 0.0002 & 0.1 & 0.001 \\
\hline \multicolumn{9}{|l|}{ Toddlers } \\
\hline - age $1.5-2.5$ years & 0.04 & 0.0008 & 0.04 & $<0.00005$ & 0.04 & 0.0002 & 0.4 & 0.001 \\
\hline - age $2.5-3.5$ years & 0.03 & 0.001 & 0.03 & $<0.00005$ & 0.03 & 0.0003 & 0.4 & 0.002 \\
\hline - age $3.5-4.5$ years & 0.03 & 0.0009 & 0.03 & $<0.00005$ & 0.03 & 0.0003 & 0.3 & 0.002 \\
\hline
\end{tabular}

4 PFAS $=\Sigma$ PFCs The estimates for PFAS are both upper and lower bound. Intake estimates are consumer rather than population based, 5 where the non-consumers of a given food type are excluded, resulting in higher values. 
Table 8. Estimated high-level 97.5 percentile UK dietary intakes ( $\mu \mathrm{g} / \mathrm{kg}$ bodyweight/day) of fluorinated chemicals by consumers of different age ranges from the diet in 2007-08

\begin{tabular}{|c|c|c|c|c|c|c|c|c|}
\hline \multirow[t]{3}{*}{ Food group } & \multicolumn{8}{|c|}{ Estimated average dietary exposure ( $\mu \mathrm{g} / \mathrm{kg}$ bodyweight/day) } \\
\hline & \multicolumn{2}{|c|}{ PFOS } & \multicolumn{2}{|c|}{ PFOA } & \multicolumn{2}{|c|}{ PFOSA } & \multicolumn{2}{|c|}{ PFAS } \\
\hline & Upper & Lower & Upper & Lower & Upper & Lower & Upper & Lower \\
\hline Senior citizens & sera & & & & & & & \\
\hline - living at home & 0.02 & 0.004 & 0.02 & 0.0002 & 0.02 & 0.002 & 0.2 & 0.007 \\
\hline - in old peoples' homes & 0.02 & 0.003 & 0.02 & 0.0001 & 0.02 & 0.001 & 0.2 & 0.004 \\
\hline Adults & 0.02 & 0.006 & 0.02 & 0.0002 & 0.02 & 0.002 & 0.2 & 0.009 \\
\hline \multicolumn{9}{|l|}{ Schoolchildren } \\
\hline -age 4-6 years & 0.05 & 0.006 & 0.04 & 0.0002 & 0.05 & 0.002 & 0.5 & 0.01 \\
\hline -age $7-10$ years & 0.05 & 0.004 & 0.03 & 0.0001 & 0.03 & 0.002 & 0.3 & 0.006 \\
\hline -age $11-14$ years & 0.02 & 0.003 & 0.02 & 0.0001 & 0.02 & 0.001 & 0.2 & 0.004 \\
\hline -age $15-18$ years & 0.02 & 0.003 & 0.02 & 0.0001 & 0.02 & 0.001 & 0.2 & 0.006 \\
\hline \multicolumn{9}{|l|}{ Toddlers } \\
\hline - age $1.5-2.5$ years & 0.08 & 0.005 & 0.08 & 0.0001 & 0.08 & 0.001 & 0.9 & 0.007 \\
\hline - age 2.5-3.5 years & 0.08 & 0.007 & 0.08 & 0.0002 & 0.08 & 0.002 & 0.8 & 0.01 \\
\hline - age $3.5-4.5$ years & 0.06 & 0.005 & 0.06 & 0.0002 & 0.06 & 0.002 & 0.6 & 0.008 \\
\hline
\end{tabular}

PFAS $=\Sigma$ PFCs 
Table 9. Illustrative intakes ( $\mu \mathrm{g} / \mathrm{kg}$ bodyweight/day) of PFOS and PFOSA from selected fish compared to remainder of diet.

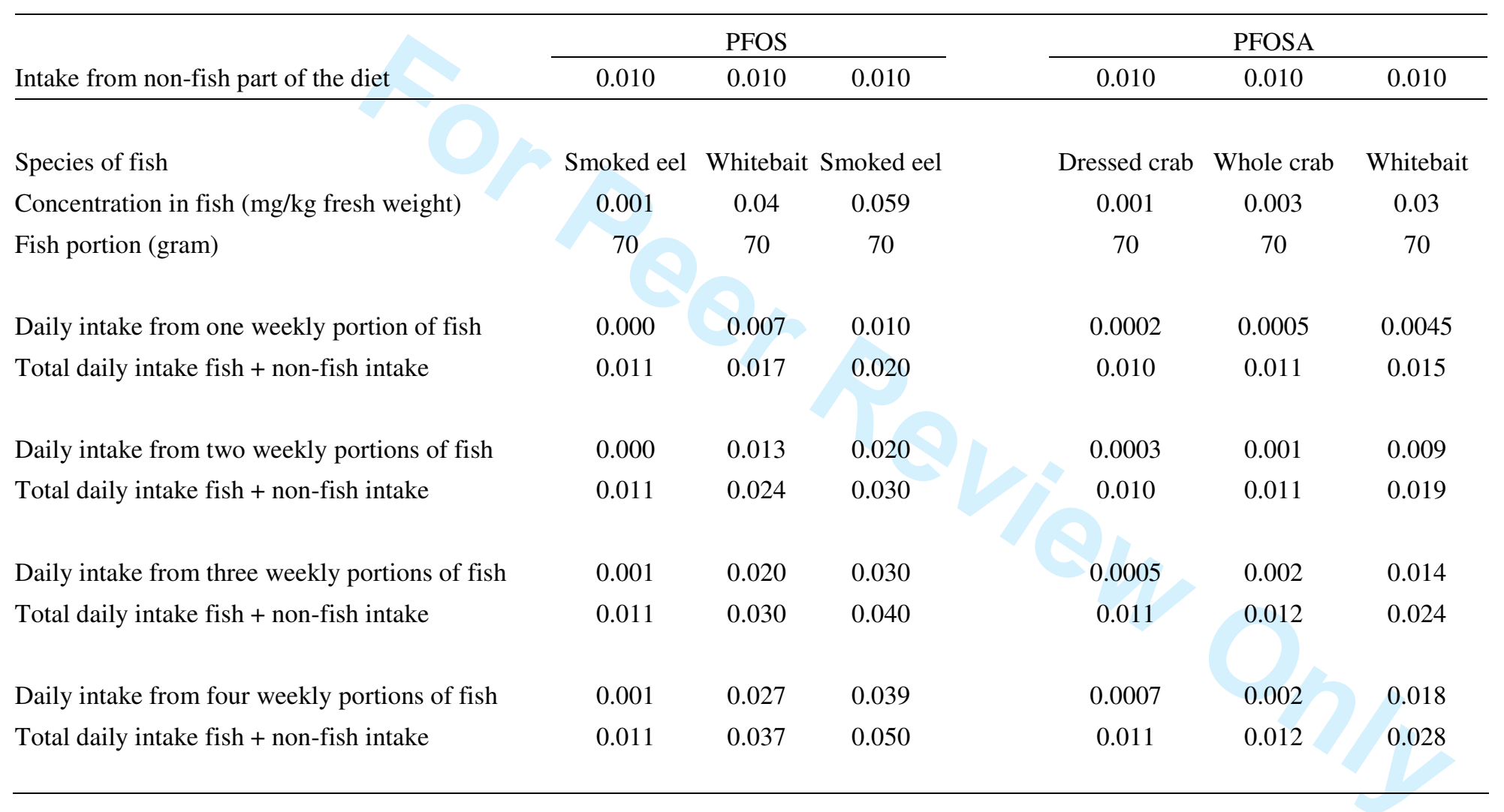

Based on representative fish in this survey from Table 4. 


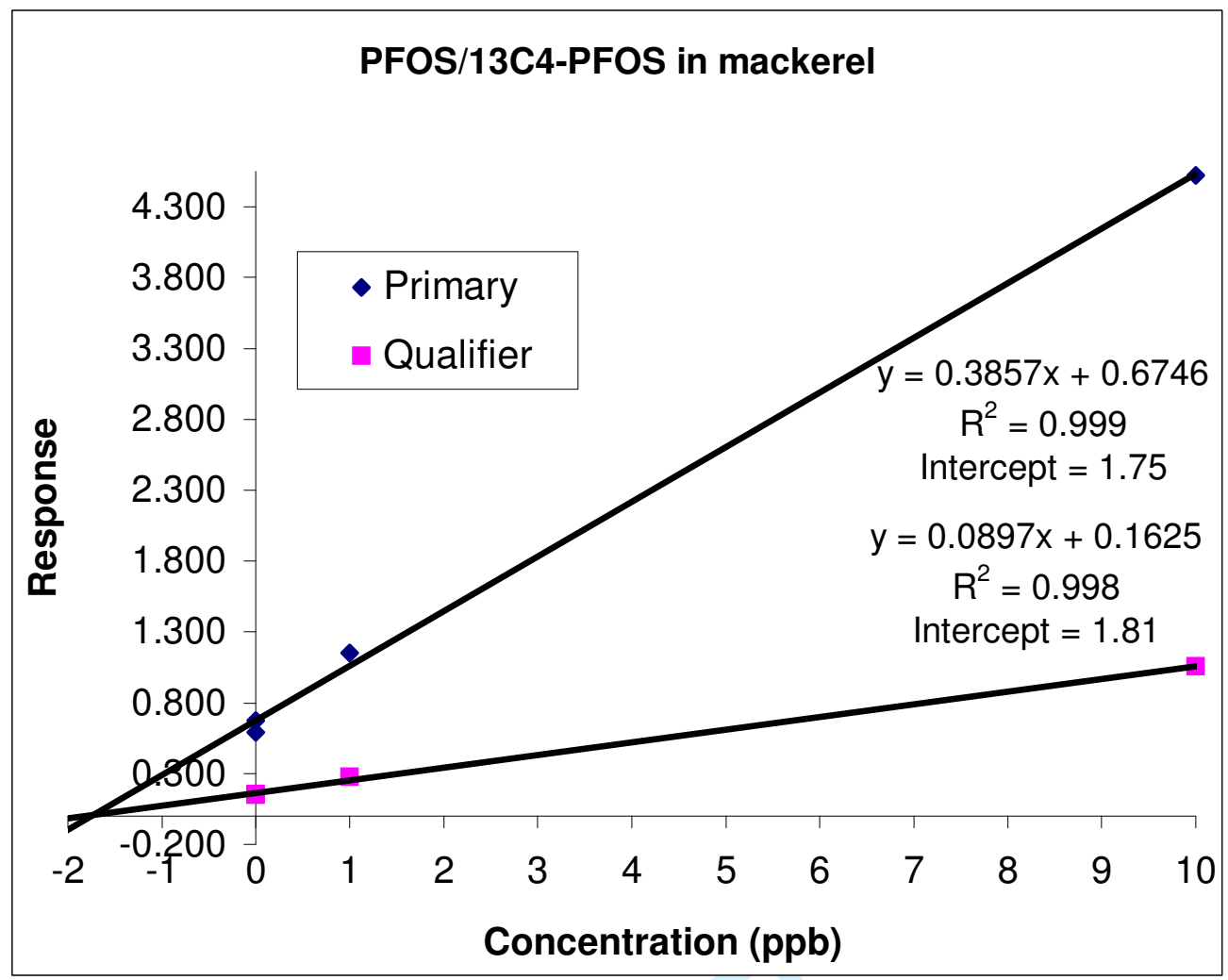

Figure 1. Standard addition calculation procedure for an English mackerel fish sample. Both sets of ion responses are first normalised to the ${ }^{13} C_{4}$-PFOS isotope dilution internal standard. The result is calculated where the line crosses the $x$-axis. Data are rounded to 1 significant figure, this sample was reported as PFOS contamination of $2 \mu \mathrm{g} / \mathrm{g}$ (primary 1.75, qualifier 1.81). The qualifying ion has a constant $24 \%$ of the response of the primary ion response (0.0897/0.3857). The average ion ratio for native and overspiked PFOS is equivalent to the precision ratio, $1.81 / 1.754 \%$. 


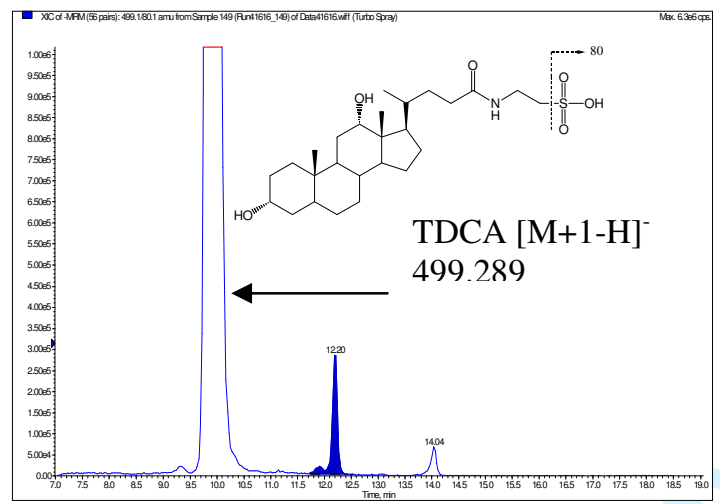

A) Unspiked sample

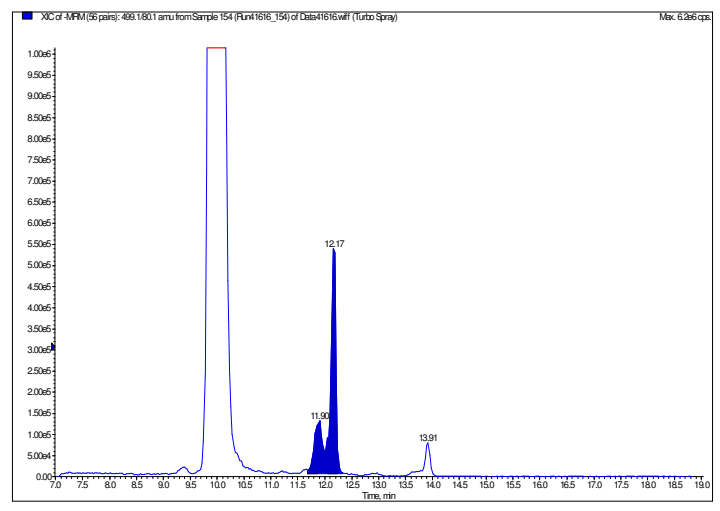

D) Overspiked sample $10 \mu \mathrm{g} / \mathrm{kg}$

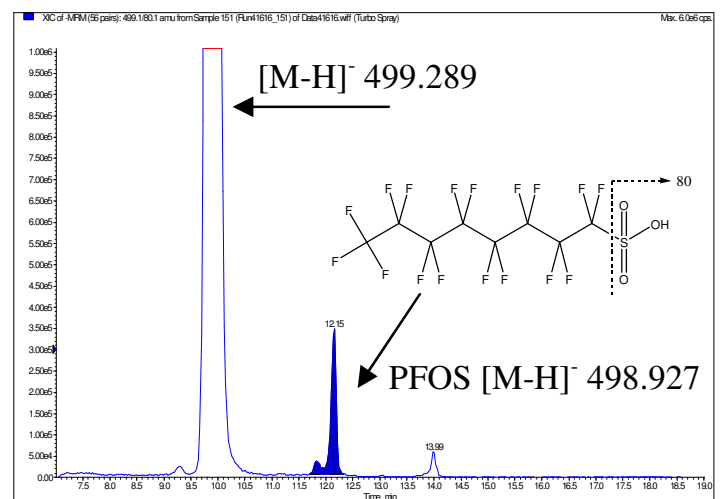

B) Overspiked at $1 \mu \mathrm{g} / \mathrm{kg}$

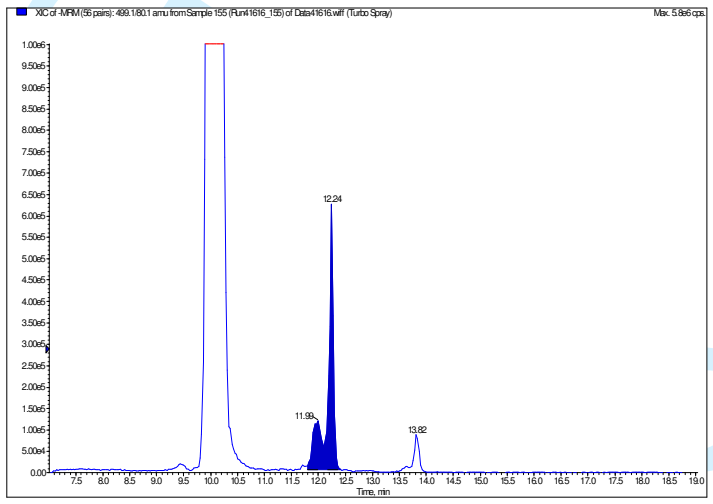

E) Overspiked at $20 \mu \mathrm{g} / \mathrm{kg}$

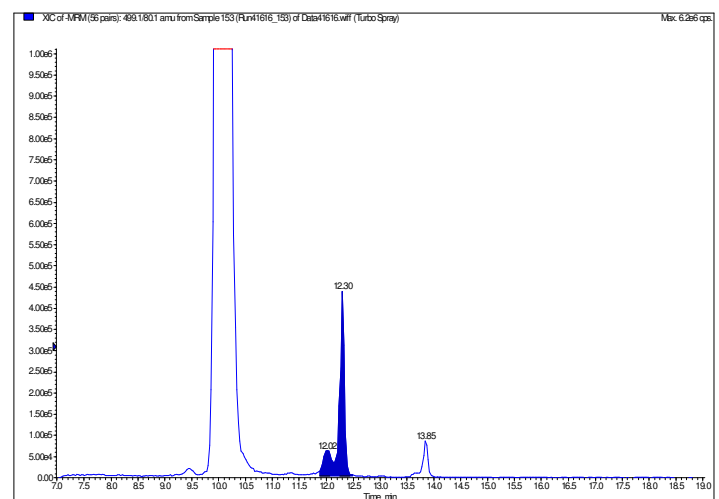

C) Over spiked at $5 \mu \mathrm{g} / \mathrm{kg}$

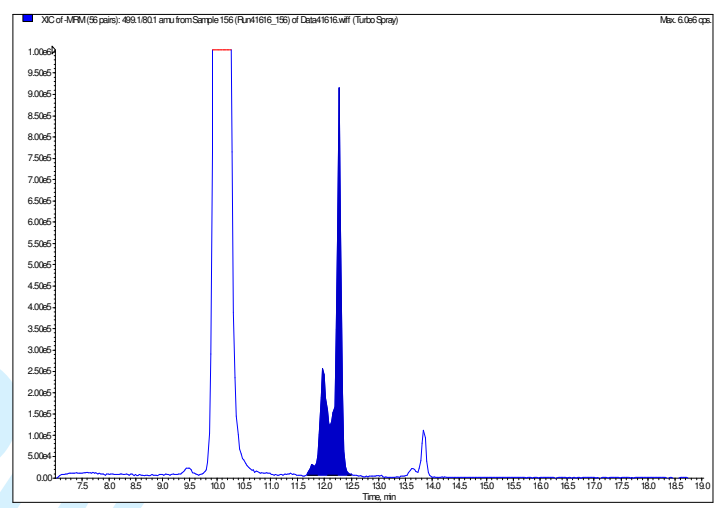

F) Over spiked at $50 \mu \mathrm{g} / \mathrm{kg}$

Figure 2. A) Chromatogram of the primary ion $499.1>80.1\left[\mathrm{M}>\mathrm{SO}_{3}\right]^{-}$for PFOS in a sample of whitebait (sample 3 in Table 1, containing $15 \mu \mathrm{g} / \mathrm{kg}$ naturally incurred PFOS) using; A) unspiked sample, B) overspiked at $1 \mu \mathrm{g} / \mathrm{kg}$, C) overspiked at $5 \mu \mathrm{g} / \mathrm{kg}$, D) overspiked at 10 $\mu \mathrm{g} / \mathrm{kg}$, E) overspiked at $20 \mu \mathrm{g} / \mathrm{kg}$ and F) overspiked at $50 \mu \mathrm{g} / \mathrm{kg}$. Other peaks in this MRM are most likely due to epimers of taurodeoxycholic acid, specifically the ${ }^{13} \mathrm{C}_{1}$ native abundance $\mathrm{M}+1$ isotope . 


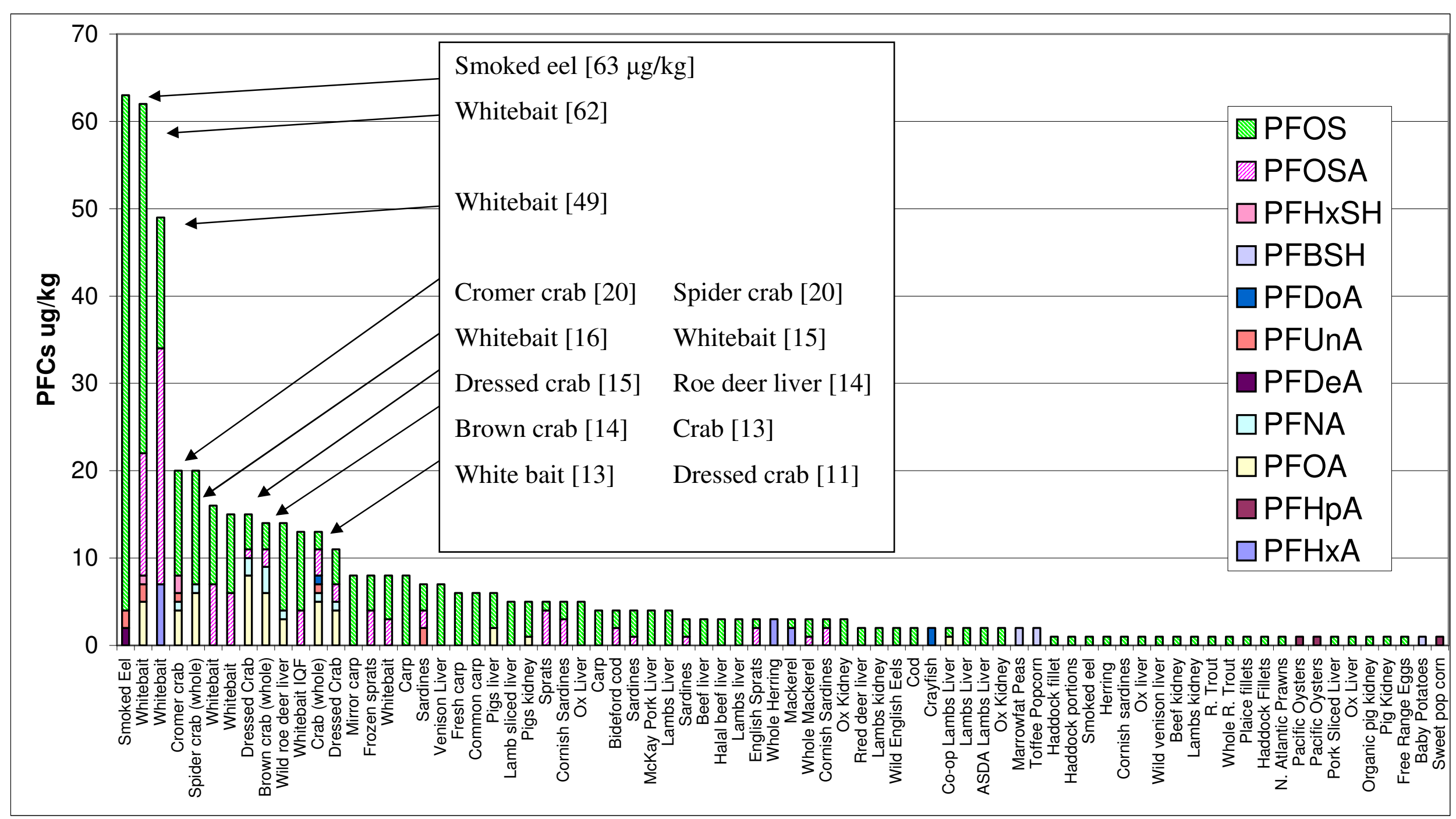

Figure 3. Distribution of individual PFCs $(\mu \mathrm{g} / \mathrm{kg})$ in 75 contaminated foods. The majority of these, 68 foods, contained PFOS, 20 contained PFOSA and 11 contained PFOA. 